

\title{
Residual stress field in steel samples during plastic deformation and recovery processes
}

Roman Wawszczak, Andrzej Baczmanski, Chedly Braham, Wilfrid Seiler, Miroslaw Wróbel, Krzysztof Wierzbanowski, Alain Lodini

\section{- To cite this version:}

Roman Wawszczak, Andrzej Baczmanski, Chedly Braham, Wilfrid Seiler, Miroslaw Wróbel, et al.. Residual stress field in steel samples during plastic deformation and recovery processes. Philosophical Magazine, 2011, pp.1. 10.1080/14786435.2011.557401 . hal-00677965

\section{HAL Id: hal-00677965 https://hal.science/hal-00677965}

Submitted on 11 Mar 2012

HAL is a multi-disciplinary open access archive for the deposit and dissemination of scientific research documents, whether they are published or not. The documents may come from teaching and research institutions in France or abroad, or from public or private research centers.
L'archive ouverte pluridisciplinaire HAL, est destinée au dépôt et à la diffusion de documents scientifiques de niveau recherche, publiés ou non, émanant des établissements d'enseignement et de recherche français ou étrangers, des laboratoires publics ou privés. 




\section{Residual stress field in steel samples during plastic deformation and recovery processes}

\begin{tabular}{|c|c|}
\hline Journal: & Philosophical Magazine \& Philosophical Magazine Letters \\
\hline Manuscript ID: & TPHM-10-Jul-0359.R1 \\
\hline Journal Selection: & Philosophical Magazine \\
\hline $\begin{array}{r}\text { Date Submitted by the } \\
\text { Author: }\end{array}$ & 20-Dec-2010 \\
\hline Complete List of Authors: & $\begin{array}{l}\text { Wawszczak, Roman; AGH-University of Science and Technology, } \\
\text { Faculty of Physics and Applied Computer science } \\
\text { Baczmanski, Andrzej; AGH University of Science and Technology, } \\
\text { Faculty of Physics and Applied Computer Science } \\
\text { Braham, Chedly; Arts et Métiers ParisTech (ENSAM), PIMM } \\
\text { Seiler, Wilfrid; Arts et Métiers ParisTech (ENSAM), PIMM } \\
\text { Wróbel, Mirosław; AGH University of Science and Technology, Metal } \\
\text { Engeenering and Industrial Computer Science } \\
\text { Wierzbanowski, Krzysztof; AGH-University of Science and } \\
\text { Technology, Faculty of Physics and Applied Computer science } \\
\text { Lodini, Alain; University of Reims Champagne-Ardenne, LACMDTI }\end{array}$ \\
\hline Keywords: & $\begin{array}{l}\text { X-ray diffraction, residual stress, plasticity of metals, recovery, } \\
\text { recrystallization }\end{array}$ \\
\hline Keywords (user supplied): & stacking fault energy, deformation model \\
\hline
\end{tabular}

\section{SCHOLARONE Manuscripts}




\section{Introduction}

Mechanical or/and thermal treatment applied to a polycrystalline sample can generate a field of internal stresses. Usually the stress field is heterogeneous and anisotropic. In many processes internal stresses are retained after the treatment. These stresses are called residual stresses and they can be described at different scales of interest [1,2]. The first order residual stresses (macrostresses), $\sigma_{i j}^{I}$, are the mean stresses averaged over a large sample volume $\left(V_{A}\right)$ containing many polycrystalline grains:

$$
\sigma_{i j}^{I}=\frac{1}{V_{\mathrm{A}}} \int_{V_{\mathrm{A}}} \sigma_{i j}(\mathbf{r}) d V
$$

where $\sigma_{i j}(\mathbf{r})$ is the local stress tensor at $\mathbf{r}$ position.

These stresses arise from mechanical or thermal treatment due to heterogeneous deformation of different parts of the material. The deviation of the stress in a particular grain (denoted by $g$ ) from the first order value is characterized by the second order residual stresses:

$$
\sigma_{i j}^{I I g}=\sigma_{i j}^{g}-\sigma_{i j}^{I} \text {. }
$$

where $\sigma_{i j}^{g}$ is the mean stress in the grain $g$. The second order stresses, called also the incompatibility stresses or microstresses, occur because of material heterogeneity, e.g., due to the mismatch in coefficient of thermal expansion, elastic constants or differences in the

\footnotetext{
* Corresponding author. Email: baczman@ftj.agh.edu.pl
} 
plastic flow between grains of the polycrystalline material. Finally, the third-order residual stresses $\sigma^{I I I}(\mathbf{r})$ characterize the heterogeneity of a single grain and originate from such phenomena as local stress fields around defects of the lattice (e.g., single dislocations or dislocation walls):

$$
\sigma_{i j}^{I I I}(\mathbf{r})=\sigma_{i j}(\mathbf{r})-\sigma_{i j}^{g} .
$$

Obviously, the stress at a given point is the sum of the first, the second and the third order stress components:

$$
\sigma_{i j}(\mathbf{r})=\sigma_{i j}^{I}+\sigma_{i j}^{I I g}+\sigma_{i j}^{I I I}(\mathbf{r})
$$

Residual stress of each type contributes to the stored elastic energy remaining in the material after deformation process. The residual stresses produce distortion of the crystallographic lattice, which can be observed in diffraction as the displacement, asymmetries and broadening of the recorded peak [3-5]. Analysis of such effects enables us not only to measure the internal stresses but also to determine the elastoplastic properties of polycrystalline materials [6-8].

The main advantages of diffraction methods are their non-destructive character and the possibility of macrostress and average micro-stress analysis for multiphase and anisotropic materials. Neutron and X-ray diffraction experiments with multiple reflections have been used successfully to determine the average plastic incompatibility stresses $\sigma_{i j}^{I I g(p i)}$ (due to mismatch of the plastic deformation in neighbouring grains) directly from the lattice strains measured for groups of crystallites contributing to different reflections $[9,10]$.

Knowledge of the dependence between the distribution of the crystallographic orientations in the polycrystalline material (described by the orientation distribution function, shortly ODF [11]) and the distribution of the residual stresses (described by the stress orientation distribution function, shortly SODF) can be useful for tailoring the material anisotropy. Significant effort has been done to determine SODF from the lattice strains measured for many orientations of the scattering vectors and for different $h \mathrm{kl}$ reflections. For this purpose the components of stress tensor (depending on lattice orientation) are usually expanded into generalised spherical harmonics [12-16] and correlated with the measured lattice strains. In this methodology, at least 5-6 independent $h k l$ reflections have to be used. However, usually such measurements are not possible in the conventional laboratory diffractometry due to low intensity of the measured diffraction peaks, especially for textured materials (they are possible in neutron TOF and energy-dispersive synchrotron XRD methods). Finally, to obtain a unique solution of SODF additional assumptions such as minimum of stress or strain variance [14-16] or stress-strain relation based on Hill's constraint tensor $[12,13]$ are needed.

Another methodology, developed by authors of the present paper, combines the diffraction data with predictions of the physical behaviour of crystallites during the material deformation calculated by elasto-plastic models. For this purpose, the self-consistent model was successfully applied [17,18]. This method allows a quantitative evaluation of the macrostresses, $\sigma_{i j}^{I}$, and the average plastic incompatibility stresses - $\sigma_{i j}^{I I g(p i)}$ (i.e., the second order intergranular stresses generated due to plastic deformation). Such methodology was described in detail in our previous works and some examples of its application to plastically deformed single and two-phase materials with cubic and hexagonal structure were shown [17-22]. In these works the residual stresses were determined using classical laboratory Xray diffraction or neutron TOF method. The methodology was also applied to determine SODF and specific elastic energy stored in the unloaded material (SSEE -specific stored elastic energy), related to the first and the second order residual stresses, induced by plastic deformation [23-25]. Additionally, the influence of tensile load on the stress field and the 
stored energy was studied. It was confirmed that, the external uniaxial stress superposes with the internal residual stresses and in elastic range of macroscopic deformation the process is fully reversible at the level of polycrystalline grains, i.e., relaxation of the second order stresses is not observed and the residual stress field remains unchanged after unloading of the sample [23]. On the contrary, even small plastic deformation (a few percent) modifies significantly residual stresses, which mostly depends on the symmetry of the imposed deformation. It was found that the influence of crystallographic texture and of initial residual stresses on the final residual stress is often not significant; moreover the sample easily "forgets" its initial stress stage [24].

The knowledge of residual stress and of corresponding stored elastic energy distributions versus crystal orientation is an important information concerning material properties. It is very useful in the study of recrystallization kinetics and especially in modelling of this process. In the recent study of recrystallization process using Monte Carlo and Vertex models [26,27], the distribution of the stored energy (connected with dislocation density) played a leading role. Also the second order residual stresses remaining after recovery process would influence the recrystallization. The characterization of stress field is also of primary importance in the study of mechanical behaviour of polycrystalline materials, including plasticity [28], fracture and damage phenomena [29-31]. Indeed, the critical stress initiating plastic deformation or damage at the grain level depends on the external load subjected to the sample but also on the first and second order residual stresses. It is known that stress field significantly changes during sample annealing. This phenomenon has an important practical application for relaxation of the residual stresses induced in machined and formed parts or in deposited coatings. These undesirable stresses can contribute to cracking when the parts are used. For example, tensile residual stresses can initiate and accelerate crack growth and they can result in failure of the coating when the external loads are superimposed. For these reasons, stress relieving process is often necessary.

Thermal relaxation of the first and the third order stresses was already deeply studied [32-35], while the evolution of the second order stresses during recovery process was not yet investigated. In the present work our methodology of stress determination is applied to study the evolution of a stress field in cold rolled ferritic and austenitic steels subjected to thermal treatment at different temperatures. The aim of this work is to describe the evolution of both the first and the second order residual stresses and corresponding stored elastic energy during recovery of plastically deformed metals. To complete the description of the processes occurring during annealing, the stress relaxation is correlated with variation of the diffraction peak width (related to the density of dislocations and the third order stresses) and with the crystallographic texture. The results of this work can be directly used in the study of mechanical properties (yield stress, damage initiation) and of recrystallization process, i.e., the values of determined grain stresses, characterizing initial sample, are the input data for deformation $[28,31]$ or recrystallization models $[26,27]$.

\section{Elastoplastic deformation models}

As mentioned above, thermal relaxation of stresses was studied by diffraction methods, however, in the analysis of experimental data the results of elastoplastic deformation models were used. These models enable us to predict the second order incompatibility stresses $\left(\sigma_{i j}^{I I g(p i)}\right)$ generated by a deformation process in a material. These stresses arise due to the anisotropy of plastic flow in different grains. The scheme of behaviour of two exemplary grains having various orientations of slip systems with respect to the local stress $(\sigma)$ is shown in Fig. 1. The local stress is the result of the macroscopic stress $(\Sigma)$ applied to the 
sample. After plastic deformation and unloading of the boundary forces (i.e., $\Sigma \rightarrow 0$ ), the grains do not fit to the surrounding mean matrix. Due to such misfit of grains, the second order incompatibility stress and corresponding lattice strain arise.

To predict plastic incompatibility stresses two scale transition models, assuming different approaches concerning localization of stresses in polycrystalline grains, were applied. In both models elastoplastic deformation is considered at two scales, i.e., for a grain and for a polycrystalline material.

\subsection{Deformation of polycrystalline grain}

On the grain-scale, plastic deformation occurs due to slip on the crystallographic planes. According to Schmid's law, the slip can be activated only on such slip system [uvw] (hkl) (the slip direction and slip plane are specified) for which the resolved shear stress $\sigma_{[u v w](h k l)}(\boldsymbol{g})$ reaches a critical value $\tau_{c}$, i.e. [36-38]:

$$
\begin{gathered}
\sigma_{[u w w](h k l)}(\boldsymbol{g})=\tau_{c}, \\
\text { where : } \quad \sigma_{[u v w](h k l)}(\boldsymbol{g})=\frac{1}{2}\left(m_{i} n_{j}+n_{i} m_{j}\right) \sigma_{i j}^{g}(\boldsymbol{g}),
\end{gathered}
$$

$\boldsymbol{g}$ is the orientation of grain lattice, $\boldsymbol{n}=\left[n_{1}, n_{2}, n_{3}\right]$ is the unit vector normal to the $(h k l)$ slip plane and $\boldsymbol{m}=\left[m_{1}, m_{2}, m_{3}\right]$ is the unit vector parallel to the $[u v w]$ slip direction.

During plastic deformation, the multiplication of dislocations and evolution of their spatial distribution inside grains leads to the hardening of slip systems ( $\tau_{c}$ increases with deformation). The hardening of slip system can be approximately described by the work hardening matrix relating the rate of the critical shear stress on the $s$-th system $\left(\dot{\tau_{c}^{s}}\right)$ with the rate of the plastic glide $\left(\dot{\gamma}^{t}\right)$ on the $t$-the active system [36-38], i.e.:

$$
\dot{\tau_{c}^{s}}=\sum_{t} H^{s t} \dot{\gamma^{t}}
$$

where dot denotes time derivative $\frac{\partial}{\partial t}$.

Slips on the crystallographic planes cause deformation of the grain $g$ and rotation of its crystal lattice, which can be described by the plastic strain rate $\dot{\varepsilon}_{i j}^{g(p l)}(\boldsymbol{g})$ and the lattice rotation rate $\dot{w}_{i j}^{g(r)}(\boldsymbol{g})$ tensors, respectively [36-38]:

$$
\dot{\varepsilon}_{i j}^{g(p l)}(\boldsymbol{g})=\frac{1}{2} \sum_{t}\left(m_{i}^{t} n_{j}^{t}+n_{i}^{t} m_{j}^{t}\right) \dot{\gamma}^{t} \quad \text { and } \quad \dot{w}_{i j}^{g(c r)}(\boldsymbol{g})=-\frac{1}{2} \sum_{t}\left(m_{i}^{t} n_{j}^{t}-n_{i}^{t} m_{j}^{t}\right) \dot{\gamma}^{t}
$$

To predict elastoplastic deformation of polycrystalline material, the relations between global variables ( $\Sigma_{i j}, E_{i j}$ - stresses and strains applied to the sample) and the local variables $\left(\sigma_{i j}^{g}(\boldsymbol{g}), \varepsilon_{i j}^{g}(\boldsymbol{g})\right.$ - stresses and strains defined for a grain) have to be established.

To this aim the idea of scale transition theory based on the self-consistent approach [36-38] and Leffers-Wierzbanowski (LW) [39-41] model are used in this work. These 
models are fully described in the mentioned references, hence only basic characteristics of them are recalled in two following sub-sections.

\subsection{Scale transition models}

\section{(1) Leffers-Wierzbanowski model}

The LW plastic model is based on that of Leffers [39] and developed and generalised by Wierzbanowski $[40,41]$ with some concepts of the self-consistent method and of the workhardening mechanism. The scale transition law in LW model is based on Hill theory [42], which defines the stress rate of a grain $\dot{\sigma}_{i j}^{g}(\boldsymbol{g})$ as the sum of the rates of the applied $\dot{\Sigma}_{i j}$ and the grain interaction stresses, i.e.:

$$
\sigma_{i j}^{g}(\boldsymbol{g})=\dot{\Sigma}_{i j}+L_{i j k l}^{*}\left(\dot{E}_{k l}-\varepsilon_{k l}^{g}(\boldsymbol{g})\right)
$$

where $\boldsymbol{L}^{*}$ is the so-called Hill's constraint tensor relating the rate of interaction stresses with the difference between the sample $\left(\dot{E}_{k l}\right)$ and the grain $\left(\dot{\varepsilon}_{k l}(\boldsymbol{g})\right)$ strain rates. It is assumed in LW model that total strain can be replaced by the plastic one if the plastic range of deformation is studied. Therefore the grain stress rate is:

$$
\dot{\sigma_{i j}^{g}}(\boldsymbol{g})=\dot{\Sigma}_{i j}+L_{i j k l}^{*}\left(\dot{E_{k l}^{(p l)}}-\varepsilon_{k l}^{g(p l)}(\boldsymbol{g})\right)
$$

In such a way one has an explicit relation for local stress if the applied stress and sample and grain plastic strains are known.

The second term of Eq. 10 describes the interaction stresses resulting from the incompatibilities of a grain with the surrounding aggregate (called matrix), caused by different sample and grain plastic strain rates. In the standard version of LW model, the $\boldsymbol{L}^{*}$ constraint tensor is replaced by the product of the elastic shear modulus $\mu$ of the studied material and the so-called elastoplastic accommodation parameter $\alpha$ [43], i.e.,:

$$
\begin{aligned}
& L_{i j k l}^{*}=\alpha \mu u_{i j} \quad \text { for } i j=k l \\
& L_{i j k l}^{*}=0 \quad \text { for } i j \neq k l
\end{aligned}
$$

where: $u_{i j}$ (equals to 0 or 1 ) describes the anisotropy of elastoplastic accommodation, while $\alpha$ can change from 0 (Sachs model [44]) up to infinity (Taylor model [45]) and reflects interactions between a grain and the surrounding matrix.

The elastoplastic accommodation parameters are free factors which can be modified in order to find the best agreement of the model results with those obtained experimentally.

\section{(2) self-consistent elastoplastic model}

In the self-consistent model the idea of scale transition theory is based on the hypothesis of the existence of a concentration tensor $A_{i j k l}^{g}(\boldsymbol{g})$ relating the macrostrain rate $\dot{E}_{k l}$ with the grain strain rate $\dot{\varepsilon_{i j}^{g}}(\boldsymbol{g})$, i.e.[36-38]:

$$
\stackrel{\dot{\varepsilon}}{\dot{\varepsilon}}(\boldsymbol{g})=A_{i j k l}^{g}(\boldsymbol{g}) \dot{E}_{k l}
$$

The polycrystalline material in macroscopic scale is approximated by a homogeneous continuum characterized by effective $L_{i j k l}^{\text {eff }}$ tangent modulus tensor relating the global strain $\left(\dot{E}_{k l}\right)$ and the stress $\left(\dot{\Sigma}_{i j}\right)$ rates: 


$$
\dot{\Sigma}_{i j}=L_{i j k l}^{e f f} \dot{E}_{k l}
$$

Assuming that the grain behaviour is described by:

$$
\dot{\sigma}_{i j}^{g}(\boldsymbol{g})=l_{i j k l}^{g}(\boldsymbol{g}) \dot{\varepsilon}_{k l}^{g}(\boldsymbol{g})
$$

the effective tensor $L_{i j k l}^{e f f}$ can be expressed through:

$$
L_{i j k l}^{e f f}=\sum_{g=1}^{N g} f^{g} l_{i j m n}^{g}(\boldsymbol{g}) A_{m n k l}^{g}(\boldsymbol{g})
$$

where: $l_{i j m n}^{g}(\boldsymbol{g})$ is a local tangent modulus tensor (depending on a choice of active slip systems), $f^{g}$ is a volume fraction of $g$-th grain and $N_{g}$ is the number of grains.

The aim of the self-consistent method is to find such concentration tensor $A_{m n k l}^{\mathrm{g}}(\boldsymbol{g})$ for which the local and global relations given by Eqs. 13 and 14 are simultaneously fulfilled. In this study, the "one-site" self-consistent approximation is used for the calculation of the strain and stress concentration tensors [36-38] and consequently:

$$
\left[A^{\mathrm{g}}(\boldsymbol{g})\right]_{i j k l}^{-1}=I_{i j k l}-T_{i j m n}^{\mathrm{gg}}(\boldsymbol{g})\left[l_{m n k l}^{\mathrm{g}}(\boldsymbol{g})-L_{m n k l}^{\mathrm{eff}}\right]
$$

where $T_{i j m n}^{\mathrm{gg}}(\boldsymbol{g})$ is an interaction tensor calculated for ellipsoidal shape of inclusion embedded in a homogenous medium with a tangent modulus $L_{i j k l}^{\text {eff }}$ and $I_{i j k l}$ is the fourth-rank unit tensor. The above interaction tensor is calculated as:

$$
T_{i j m n}^{g g}=\frac{1}{V_{g}} \int_{V_{g} V_{g}} \int_{i j m n}\left(\mathbf{r}, \mathbf{r}^{\prime}\right) d V d V^{\prime}
$$

where $\Gamma_{i j m n}$ is the Green tensor [36] and $\mathbf{r}, \mathbf{r}^{\prime}, d V, d V^{\prime}$ vary within the grain $g$ of the volume $V_{g}$.

Comparing Eq. 15 with Eq. 16, it can be concluded that the $L_{i j k l}^{\text {eff }}$ tensor can be calculated only if the $A_{m n k l}^{\mathrm{g}}(\boldsymbol{g})$ tensor is known, and vice versa. To find both tensors, the self-consistent procedure must be used. Knowing the $A_{m n k l}^{\mathrm{g}}(\boldsymbol{g})$ and $L_{i j k l}^{\text {eff }}$ tensors, the rate of strain at grain $\dot{\varepsilon_{i j}^{g}}(\boldsymbol{g})$ can be determined from a global strain rate $\dot{E}_{k l}$ (Eq. 12) or from the stress rate $\dot{\Sigma}_{k l}$ (Eqs. 12 and 13). Subsequently, other variables (see section 2.1) characterizing grain evolution and depending on $\dot{\varepsilon}_{i j}^{\mathrm{g}}(\boldsymbol{g})$ rate can be calculated.

\subsection{Numerical algorithm}

An incremental formulation of the above models was developed for its numerical implementation. Calculations are performed for a given set of polycrystalline grains (in the case of self-consistent model represented by ellipsoidal inclusions) characterized by single crystal elastic constants, initial lattice orientations and initial critical resolved shear stresses for slip systems. In this procedure, all local and global variables describing the polycrystal are known at the end of step (i-1). For current values of grain stresses $\sigma_{i j}^{\mathrm{g}}(\boldsymbol{g})$ and critical resolved stresses $\tau_{c}^{s}$, the Schmid's criterion (Eq. 5) is checked and the active slip systems 


\subsection{Differences between applied models and assumptions used in calculations}

The models applied in this work approximate plastic deformation of polycrystalline material using different assumptions concerning localization of the stress (or strain) in grains. Nevertheless, the calculations are based on the same scheme (described above) and many assumptions are common for both algorithms. Let us specify the differences and similarities between models, explaining advantages and reasons of the used approximations for our methodology.

\section{Assumptions common for both models (at grain level):}

- The Schmid's criterion (Eq. 5) is used to select combination of slip system active during increment $\Delta \Sigma_{k l}$ or $\Delta E_{k l}$. The same value of initial critical resolved shear stress was assumed for all grains.

- A constant value of the $H$ parameter is assumed for all components of hardening matrix (i.e., $H^{s t}=H$ in Eq. 7), i.e. the constant and isotropic hardening is applied to generate theoretical plastic incompatibility stresses $\left(\sigma_{i j}^{I I(p i)}(\boldsymbol{g})\right.$. The reason is that the real hardening of the material cannot be measured during cold rolling process and the parameters of nonlinear law (for example Voce law [47]) cannot be found. Thus the modelling is performed with constant hardening, not for the whole process but only for some increment of deformation (specified below for the studied samples). As the result, the dependence of $\sigma_{i j} \underset{i j \approx \approx \approx z}{I I g(p)}(\boldsymbol{g})$ on grain orientation can be found, however exact magnitude of these stresses, depending on the material hardening, remains unknown. The aim of the methodology described below is to find the real values of plastic incompatibility stresses from so obtained theoretical results using X-ray diffraction data. Moreover, the simplest assumption of the isotropic hardening (i.e. 
$H^{\text {st }}=H$ in Eq. 7) was used because no improvement of the results was achieved when different values of self and latent hardening [48] were introduced in calculations.

- Experimental crystallographic texture measured for the studied sample is imposed for the initial set of grains used in calculations, i.e. orientations of the grains are distributed according to measured ODF. Rotation of grain lattice is taken into account in calculations (plastic deformation and lattice rotation are calculated according Eq. 8). Model prediction is performed for limited range of deformation for which texture is not significantly modified.

\section{Differences between models (localization approach):}

The self-consistent model used in this work is based on the local constitutive relation given by Eq. 14 and strain concentration tensor (Eq. 16) calculated for ellipsoidal inclusion embedded in homogenous medium (Eshelby type model [49]). To calculate concentration tensor the Green function technique and the self-consistent method are used [36]. Thus the stress concentration and grains interaction is determined by sample and grain properties varying during plastic deformation. Although this model is based on strict mechanical description it fails in some cases of calculations (for example the crystallographic texture of cold rolled brass cannot be correctly predicted). The main disadvantage of the model is that the concentration tensor is strictly defined and additional phenomena changing localization (for example stress relaxation on the grain boundary) cannot be taken into account in calculations. In the case of LW model the stress applied to the sample is localized in the grain according to Eq. 10. In this approach the interaction between grains is approximated by the

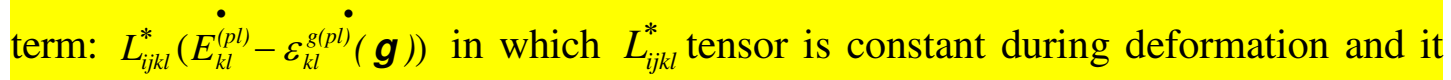
does not depend on the grain or sample properties. Although significant simplification is used in LW model, the main advantage of this algorithm is its flexibility, i.e. the interaction term can be easily modified changing accommodation parameters $\alpha$ and $u_{i j}$ in Eq. 11 (e.g. crystallographic texture can be predicted assuming small value of $\alpha[40,41])$. On the other hand LW model does not take into account the influence of elastic and plastic anisotropy on the stress localization, thus the prediction is not so accurate as with the self-consistent model (in the case when localisation is correctly described by Eshelby approach). In the present work it will be demonstrated that the differences between two described models play a key role in the prediction of plastic deformation in real sample.

\section{Experimental technique}

The $\sin ^{2} \psi$ X-ray diffraction method [3,4] of stress analysis is based on the measurement of peak positions for a given $h \mathrm{kl}$ reflection and for various orientations of the scattering vector . In the sample reference system these orientations are defined by $\phi$ and $\psi$ angles (Fig. 2). Next, the interplanar spacings $\langle d(\phi, \psi)\rangle_{\{h k l\}}$ are calculated using Bragg's law. Statistically more representative results are obtained when the average interplanar spacings $\left\langle d(\phi, \psi)_{\rangle_{\{h k l\}}}\right.$ are measured for more than one $h k l$ reflection. Then, so called multireflection method for data analysis can be used to determine the stress field from equivalent lattice parameters, defined as $\langle a(\phi, \psi)\rangle_{\{h k l\}}=\sqrt{h^{2}+k^{2}+l^{2}}\langle d(\phi, \psi)\rangle_{\{h k l\}}$ for cubic crystal 
where $s_{1}(h k l)$ and $s_{2}(h k l)$ are the diffraction elastic constants (DEC) for quasi-isotropic polycrystal, $a^{o}$ is the strain free lattice parameter and the first order stresses $\sigma_{i j}^{I}$ are defined with respect to the $X$ system (Fig. 2).

It should be stated that the measured $\langle a(\phi, \psi)\rangle_{\{h k l\}}$ parameter is defined as the mean value over the volume of diffracting grains for a chosen $h k l$ reflection (this is noted by $\langle\ldots\rangle_{\{h k l\}}$ ). Thus the diffraction elastic constants relate the first order stress $\sigma_{i j}^{I}$ (averaged over the whole gauge volume irradiated by X-rays) with the strain in the direction of the scattering vector in a given orientation (averaged over volume of selected grains for which the scattering vector is perpendicular to $\{h k l\}$ planes). The DEC can be calculated by different models from single crystal elastic constants $[3,4]$ and they are not equal to the values of macroscopic or single crystal elastic modulus. When the material is not textured (quasiisotropic) only two DEC are defined: $s_{1}(h k l)$ and $s_{2}(h k l)$. They depend on a chosen reflection $h k l$ but do not depend on the orientation of the scattering vector $(\phi, \psi)$ defining direction of strain measurement.

In the case of one phase material, due to low penetration depth of X-ray radiation, the force perpendicular to the sample surface is not present in the analysed volume, and the $\sigma_{33}^{I}$ is assumed to be zero. The $\langle a(\phi, \psi)\rangle_{\{h k l\}}$ parameters are determined as a function of $\sin ^{2} \psi$ for constant $h k l$ reflection and $\phi$ angle, as well. In this case, the above equation exhibits a linear dependence of $\langle a(\phi, \psi)\rangle_{\{h k l\}}$ vs. $\sin ^{2} \psi$ for a biaxial stress state (i.e., for $\left.\sigma_{33}^{I}=\sigma_{13}^{I}=\sigma_{23}^{I}=0\right)$ or it shows a splitting phenomenon if non-zero shear stresses $\sigma_{13}^{I}$ and $\sigma_{23}^{I}$ are present in the sample. The splitting, i.e., the opposite curvature of the $\sin ^{2} \psi$ plots, can be observed when the measurements are performed for the $\phi$ and $\phi+\pi$ angles, respectively $[3,4]$. In the conventional $\sin ^{2} \psi$ method, a linear or elliptical regression is used to determine the stresses from the $\langle a(\phi, \psi)\rangle_{\{h k l\}}$ vs. $\sin ^{2} \psi$ graphs, measured by Xray diffraction for the given $h k l$ and $\phi$ parameters. Consequently, the $\sigma_{11}^{I}, \sigma_{22}^{I}, \sigma_{12}^{I}, \sigma_{13}^{I}, \sigma_{23}^{I}$ stresses and $a^{o}$ (strain free lattice parameter) can be determined if the $\sin ^{2} \psi$ plots are measured for different $\phi$ angles.

For textured samples DECs depend on ODF and they vary with $\phi$ and $\psi$ angles. In this case the plots of $\langle a(\phi, \psi)\rangle_{\{h k l\}}$ vs. $\sin ^{2} \psi$ are no longer linear or elliptical. The measured interplanar spacingshave to be expressed by the macrostresses $\sigma_{i j}^{I}$ using a more general equation: 


$$
<a(\phi, \psi)_{\{h k l\}}=\left[F_{i j}(h k l, \phi, \psi) \sigma_{i j}^{I}\right] a^{0}+a^{0}
$$

where: $F_{i j}(h k l, \phi, \psi)$ are DEC defined for an anisotropic (textured) material.

When the polycrystalline material is textured (but second order stresses are not present) small nonlinearities appear on the $\langle a(\phi, \psi)\rangle_{\{h k l\}}$ vs. $\sin ^{2} \psi$ plots due the dependence of $F_{i j}(h k l, \phi, \psi)$ on $\psi$ angle. The magnitude of nonlinearities is proportional to the value of the first order stresses. This effect was deeply studied by many authors and different methods for calculations of $F_{i j}(h k l, \phi, \psi)$ from single crystal elastic constants and measured ODF, characterizing crystallographic texture, were proposed [4,17,18,23]. Knowing values of $F_{i j}(h k l, \phi, \psi)$ five components of macrostress tensor $\sigma_{i j}^{I}$ and $a^{o}$ strain free lattice parameter can be determined using the least square fitting procedure (the analysis of diffraction data with assumption that the second order are not taken into account will be called "standard $\sin ^{2} \psi$ method").

\subsection{Method for determination of the first and the second order stresses}

The effects of the intergranular second order stresses have been observed as strong nonlinearities of the $\langle a(\phi, \psi)\rangle_{\{h k l\}}$ vs. $\sin ^{2} \psi$ plots measured by X-ray or neutron diffraction for polycrystalline samples subjected to elastoplastic deformations [2, 12-20, 23-25]. The character and magnitude of these nonlinearities are definitively different from those which are caused only by the elastic anisotropy of textured sample (as mentioned, effect of texture can be taken into account by $F_{i j}(h k l, \phi, \psi)$ constants). Thus, not only the elastic anisotropy but mostly the second order incompatibility stresses $\left(\sigma_{i j}^{I I g}\right)$ are responsible for non-linear character of the $\langle a(\phi, \psi)\rangle_{\{h k l\}}$ vs. $\sin ^{2} \psi$ plots.

To analyse $\langle a(\phi, \psi)\rangle_{\{h k l\}}$ vs. $\sin ^{2} \psi$ curves measured for plastically deformed materials the modified $\sin ^{2} \psi$ method allowing the separation of the macrostresses $\sigma_{i j}^{I}$ and the second order plastic incompatibility stresses $\left(\sigma_{i j}^{I I g(p i)}(\boldsymbol{g})\right)$ was developed $[17,18]$. In this method it is assumed that the dependence of $\underset{i=\approx \approx \approx \approx \approx \approx \approx \approx}{\sigma_{i j}^{I g(p i)}}(\boldsymbol{g})$ on latticeorientation $\boldsymbol{g}$, can be qualitatively predicted by the elastoplastic model. However, the absolute values of the stresses will depend on the hardening during plastic deformation and on the relaxation processes occurring due to annealing. These processes are difficult to model and in general the amplitude of the stress tensor cannot be exactly predicted. To relate the magnitude of theoretical $\underset{\sigma_{i j} I I g(p)}{\sigma(\boldsymbol{g})}(\boldsymbol{g})$ stresses to the real ones, an unknown scaling factor $q$ is introduced $[17,18]$. This factor does not depend on a grain orientation $\boldsymbol{g}$ and it rescales only the amplitude of the stress tensor, i.e. the second order incompatibility stress $\sigma_{i j}^{I I g(p i)}(\boldsymbol{g})$ in the real sample is equal to:

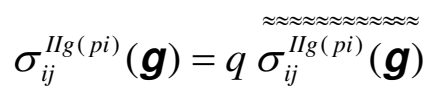

where $q$ is the scaling parameter and $\overline{\sigma_{i j}^{I I g(p i)}(\boldsymbol{g})}$ is the plastic incompatibility stress for a grain with $\boldsymbol{g}$ orientation as predicted by the elastoplastic model after sample unloading 
$\left(\Sigma_{k l} \rightarrow 0\right.$, see section 2.3$)$.

The equivalent lattice parameters $\langle a(\phi, \psi)\rangle_{\{h k l\}}$ measured in the direction of the scattering vector by use of the $\{h k l\}$ diffraction planes, can be expressed as:

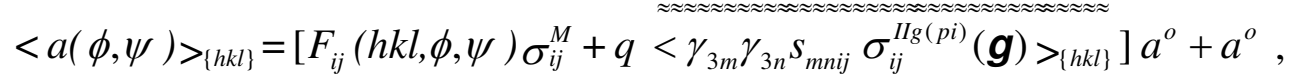

where: $s_{m n i j}(\boldsymbol{g})$ are the single crystal elastic constants defined with respect to the sample system ( $\boldsymbol{X}$ in Fig. 2), $\gamma_{\mathrm{km}}$ are the direction cosines relating strains expressed in the sample frame $(\boldsymbol{X})$ to the strain along the direction of scattering vector (see Fig. 2) and

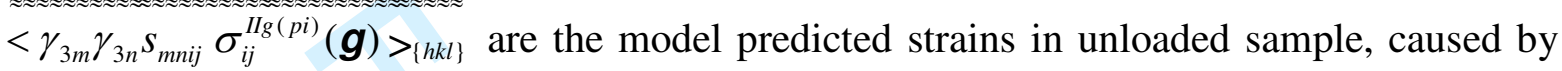
the second order plastic incompatibility stresses.

Using the least square method to adjust the calculated $\langle a(\phi, \psi)\rangle_{\{h k l\}}$ values (Eq. 20) to experimental ones, the fitting parameters (i.e., $\sigma_{i j}^{I}, q$ and $a^{o}$ ) can be determined for cold rolled and annealed samples. The procedure used in this work is based on the minimization of the merit function, called $\chi^{2}$, and defined by:

$$
\chi^{2}=\frac{1}{N-M} \sum_{n=1}^{N}\left(\frac{\left\langlea \left(\phi_{n}, \psi_{n}>_{[h k l\}}^{\exp }-<a\left(\phi_{n}, \psi_{n}>_{[h k l)}^{c a l}\right.\right.\right.}{\delta_{n}}\right)^{2}
$$

where $<a\left(\phi_{n}, \psi_{n}>_{\{h k l\}}^{\exp }\right.$ and $\left\langle a\left(\phi_{n}, \psi_{n}>_{\{h k l\}}^{c a l}\right.\right.$ are the experimental and calculated equivalent lattice parameters measured using $h k l$ reflections, $\delta_{n}=\delta_{n}\left(<a(\phi, \psi)_{\{h k l\}}\right)$ is the measurement error (standard deviation) of the determined spacing $\left\langle a(\phi, \psi)_{\rangle_{\{h k l\}}}\right.$ for the $n$-th measurement, $N$ and $M$ are the numbers of measured points and fitting parameters, respectively.

It should be emphasized that the term $<_{3 m} \gamma_{3 n} s_{m n i j} \sigma_{i j}^{I I f(p i)}(\boldsymbol{g})>_{\{h k l\}}$ predicted by the deformation model and characterizing the nonlinearities of the $\sin ^{2} \psi$ plot is adjusted to the experimental data obtained for the initial as well as annealed samples. Thus, in this approach it was assumed that the orientation distribution of the plastic incompatibility stresses does not change significantly during thermal treatment. Only the magnitude of these stresses (described by $q$ parameter in Eq. 19) decreases due to recovery processes.

\subsection{Diffraction measurements}

Cold rolled ferritic low carbon steel (reduction of 85\%) was subjected to the annealing in different temperatures $\left(200^{\circ} \mathrm{C}, 400^{\circ} \mathrm{C}, 600^{\circ} \mathrm{C}, 800^{\circ} \mathrm{C}\right)$ in $\mathrm{CO}_{2}+\mathrm{CO}$ atmosphere for 30 minutes. In the case of cold rolled austenitic stainless steel (reduction of $70 \%$ ) the annealing was performed in temperatures: $0{ }^{\circ} \mathrm{C}, 400{ }^{\circ} \mathrm{C}, 450{ }^{\circ} \mathrm{C}, 500{ }^{\circ} \mathrm{C}, 600{ }^{\circ} \mathrm{C}$ and $650{ }^{\circ} \mathrm{C}$ for 120 minutes, in argon atmosphere.

The X-ray patterns were recorded using a Seifert diffractometer, equipped with a chromium anode $\left(\lambda_{\mathrm{K} \alpha 1}=2.29090 \AA\right)$ for ferritic steel and manganese anode $\left(\lambda_{\mathrm{K} \alpha 1}=2.10310\right.$ $\AA$ ) for austenitic steel. In order to avoid surface effects the layer of $200 \mu \mathrm{m}$ was removed from each sample by electropolishing method. ODFs characterizing crystallographic textures, were calculated from measured incomplete pole figures $(\{110\},\{200\},\{211\}$ for ferrite and $\{111\},\{200\},\{220\}$ for austenite) using WIMV method [50]. The measurements were done in the range of $\alpha$ between $0^{0}$ and $65^{\circ}$ with angular step of $5^{0}$ for $\alpha$ and $\beta$. The obtained ODFs are shown in Figs. 3 and 4 for two materials and different temperatures of 
annealing. It can be seen that the distribution of orientations did not change significantly when the cold rolled ferritic steel was annealed at $200^{\circ} \mathrm{C}$ and $400^{\circ} \mathrm{C}$. A considerable modification of ODF, corresponding to the recrystallization process occurred in $600^{\circ} \mathrm{C}$. In the case of austenitic steel the texture of cold rolled sample remained almost unchanged until $600^{\circ} \mathrm{C}$ and only in $650^{\circ} \mathrm{C}$ a small but clear changes in texture typical for its transformation towards the recrystallization texture were registered.

To determine the equivalent lattice parameters $\langle a(\psi, \phi)\rangle_{\{h k l\}}$, the 211 and 200 reflections were used for ferritic steel, while the 311 and 220 reflections were used in the case of austenitic steel. In analysis of the experimental data the background approximated by linear function was subtracted from recorded diffraction peaks and $\mathrm{K}_{\alpha 2}$ component was eliminated. Then, the peaks profiles were fitted with pseudo-Voigt function and interplanar spacings were calculated from peaks positions using Bragg law. The $\langle a(\phi, \psi)\rangle_{\{h k l\}}$ vs. $\sin ^{2} \psi$ curves were determined using the side-inclination method ( $\psi$-goniometer geometry) with point focus (1.5 mm diameter of collimator). Diffraction profiles were obtained for 17 different $\psi$ directions (for $+\psi$ and $-\psi$ inclinations) in each of the four $\phi$ angles fixed at $0^{\circ}$, $30^{\circ}, 60^{\circ}$ and $90^{\circ}$ for ferrite and in three $\phi$ angles $0^{\circ}, 45^{\circ}, 90^{\circ}$ for austenite. Because of the sample symmetry the results obtained for $+\psi$ and $-\psi$ inclinations are symmetrical and they are presented in the same plot (see Figs. 5 and 6). The nonlinearities of the measured $\langle a(\phi, \psi)\rangle_{\{h k l\}}$ vs. $\sin ^{2} \psi$ curves confirmed a strong anisotropy of the second order plastic incompatibility stresses $\left(\sigma_{i j}^{I I g}(p i)(\boldsymbol{g})\right)$ in both cold rolled steels.

Finally, the integral width of diffraction peak profile was also studied (see Fig.7). Variation of this parameter is usually related to changes of dislocation density. In the ferritic steel (Fig. 7a), the integral width of the peaks (and consequently dislocation densities) decreases during samples annealing until $600^{\circ} \mathrm{C}$, where recrystallization of the material begins. Next, at $800^{\circ} \mathrm{C}$ the width of the peak (reflection 211) did not change. In the case of austenitic steel the width of the diffraction peaks decreases slightly until $400^{\circ} \mathrm{C}$, and after this threshold a significant reduction of peaks broadening occurs (see Fig. 7b).

\section{Results and discussion}

The crucial point of stress analysis is a correct modelling of the processes occurring during elastoplastic deformation. The analysis performed by so called modified $\sin ^{2} \psi$ method requires almost exact prediction of the nonlinearities on the $\langle a(\phi, \psi)\rangle_{\{h k l\}}$ vs. $\sin ^{2} \psi$ curves (only the amplitude of nonlinearities is scaled by $q$ factor). If theoretically predicted

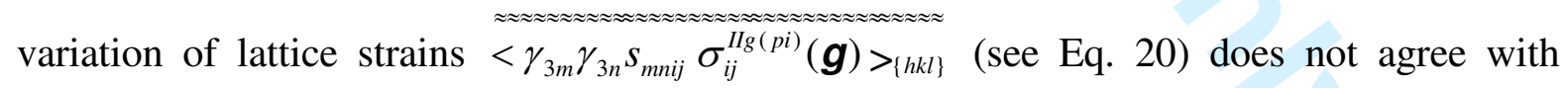
experimentally determined oscillations of $\langle a(\phi, \psi)\rangle_{\{h k l\}}$ vs. $\sin ^{2} \psi$ plots, the fitting procedure fails and the value of $q$ parameter approaches zero. The disagreement of theoretical and experimental data can be observed directly on the $\langle a(\phi, \psi)\rangle_{\{h k l\}}$ vs. $\sin ^{2} \psi$ plot and can be also quantitatively characterized by $\chi^{2}$ parameter defined in Eq. 21 .

\subsection{Determination of the second order plastic incompatibility stresses}

Model calculations were carried out for $10^{6}$ polycrystalline grains, having forms of spherical inclusions, embedded in an elastically and plastically homogeneous matrix in the case of the self-consistent model. The crystal lattice orientations were assigned according to the initial 
ODFs measured by X-ray diffraction (see Figs. 3 and 4). The initial critical resolved shear stresses $\left(\tau_{0}\right)$, the work hardening parameter $(H)$, single crystal elasticity constants $\left(C_{i j}\right)$ [51], elastic shear modulus $(\mu)$ and plastic accommodation matrix $\left(u_{i j}\right)[40,41]$ are quoted in Table 1. The two first parameters were assumed arbitrary ( $\tau_{0}$ and $H$ mostly influence magnitude of the $\sigma_{i j}^{I I g(p i)}(\boldsymbol{g})$ stresses but not significantly change their dependence on grain orientation), while the other ones are taken from the cited literature for the studied materials. It was assumed that the $\langle 110>\{111\}$ slip systems were active during plastic deformation of the austenitic sample (f.c.c. structure), while two slip system families, i.e.: $<111>\{110\}$ and $<111>\{211\}$, were active in the ferritic steel (b.c.c. structure). It should be stated that the processes occurring during large deformation (as cold rolling) cannot be exactly predicted by models due to unknown variation of hardening process. Thus to find out the orientation distribution of theoretical incompatibility stresses we perform a model calculation for a given increment of deformation for a set of grains having orientations corresponding to the crystallographic texture measured for a cold rolled sample $[23,24]$. To generate the second order plastic incompatibility residual stress, the cold rolling process followed by unloading $\left(\Sigma_{i j} \rightarrow 0\right)$ is simulated. The assumed increment of deformation should be large enough to activate sets of slip systems corresponding to those which operate in the real sample during cold rolling process. On the other hand the deformation increment should not be too large because the final model texture can be significantly modified and different from the experimental texture (initial one for model). The appropriate deformation range (usually between 5-20\%) depends on the interaction between grains as well as on the crystallographic texture and it is estimated by fitting the model lattice strains to experimental results (see procedure based on Eqs. 19 and 20). For the studied samples the best fit (the lowest value of $\chi^{2}$ ) was obtained when the model calculations were performed for the sample deformation of $E_{11}=10 \%$ for ferritic steel and $E_{11}=20 \%$ for austenitic steel.

Next, the stress analysis based on the least square fitting procedure (Eq. 20) was performed. Diffraction elastic constants $F_{i j}(h k l, \phi, \psi)$ were calculated from single crystal elastic constants (Table 1) and ODFs measured for cold rolled and annealed samples (Figs. 3 and 4), using the Free Surface Method. This method is described in [23], where also its application for textured materials was theoretically and experimentally justified. The number and distribution (with respect to $\phi$ angle) of measured $\langle a(\phi, \psi)\rangle_{\{h k l\}}$ vs. $\sin ^{2} \psi$ plots enabled us to calculate five components of the macrostress tensor with assumption that $\sigma_{33}^{I}=0$. Thus, $\sigma_{11}^{I}$ (in the rolling direction - RD), $\sigma_{22}^{I}$ (in the transverse direction - TD ) and $\sigma_{12}^{I}$, $\sigma_{13}^{I}$ and $\sigma_{23}^{I}$ components were treated as the fitting parameters. Simultaneously, the values of the strain free interplanar spacing $a^{o}$ and of $q$ scaling factor were adjusted. As expected, due to the orthorhombic sample symmetry of cold rolled materials only two principal components of the macrostress tensor $\left(\sigma_{11}^{I}\right.$ and $\sigma_{22}^{I}$ ) were significant, while the shear stresses were negligible (values of several $\mathrm{MPa}$ ). It was also verified that almost the same values of $\sigma_{11}^{I}$ and $\sigma_{22}^{I}$ stresses were obtained when other components of macrostress tensor $\left(\sigma_{12}^{I}, \sigma_{13}^{I}\right.$ and $\sigma_{23}^{I}$ ) were assumed equal to zero in fitting procedure. Thus in further analysis only the evolution of $\sigma_{11}^{I}$ and $\sigma_{22}^{I}$ stresses generated during cold rolling and modified by annealing process are considered in section 4.3. Finally, the next adjusted parameter, i.e., $q$, 
can be used to calculate the average second order plastic incompatibility stresses $\left(\sigma_{i j}^{I I g(p i)}(\boldsymbol{g})\right)$ from theoretical results $\left(\sigma_{i j}^{I I I z(p i)}(\boldsymbol{g})\right)$ for each lattice orientation $\boldsymbol{g}$ (see Eq. 19).

Before presentation of the final results of analysis, different model assumptions concerning stress localisation were tested. To verify a type of grains interaction, model calculations were done for different $\alpha$ values of accommodation parameter in LW model (see Eqs. 10 and 11). In the case of the ferritic steel the best fit of theoretical lattice strains to the experimental results was obtained for $\alpha=0.06$ (see Fig. 8a, where $\chi^{2}$ for different $\alpha$ is shown). Comparing von Mises stresses [52] averaged for all grain orientations, it was checked that for the same initial critical shear stress $\tau_{0}$ and work hardening parameter $H$ (see Table 1), the level of plastic incompatibility stresses generated by LW model with $\alpha=$ 0.06 corresponds directly to those predicted by self-consistent model. In this case an equivalent interaction level between grains occurs in both models. Additional point (*) shown in Fig. 8a presents the $\chi^{2}$ obtained from fitting procedure for theoretical strains predicted by the self-consistent model (presented at $\alpha=0.06$ ), while the horizontal dotted line corresponds to $\chi^{2}$ value resulting from assumption that the second order plastic incompatibility stresses $\left(\sigma_{i j}^{I I g(p i)}\right)$ are not taken into account. Analysing Fig. 8a, it can be concluded that both the self-consistent and LW (for $\alpha=0.06$ ) models equivalently predict distribution of plastic incompatibility stresses (practically the same $\chi^{2}$ in both cases). The quality of fitting is definitively better when plastic incompatibility stresses are taken into account in fitting procedure (compare: $\chi^{2}=12$ for standard $\sin ^{2} \psi$ method based on Eq.18 and $\chi^{2}=2.2$ when the model date are used in fitting, see Eq. 20).

Similar analysis as for ferrite was performed for the cold rolled austenitic steel. In this case, however, the best fitting of theoretical results was obtained when very low value of $\alpha$ was assumed in LW model; in fact $\chi^{2}$ decreases when $\alpha$ approaches zero value corresponding to Sachs model (Fig $8 b$ ). In Fig. 8 b also the $\chi^{2}$ values for self-consistent model (eq. 20) and for the standard $\sin ^{2} \psi$ method (Eq. 18) are shown. In the case of selfconsistent model it was checked that the level of incompatibility stresses corresponds to these predicted by LW model with $\alpha=0.09$. The advantage of LW model is that the quality of fitting can be improved by tuning of $\alpha$ parameter, what cannot be done in the case of selfconsistent model. Note, that we have achieved two times lower $\chi^{2}$ for $\alpha$ between $10^{-4}$ and $10^{-3}$ than in the case when plastic incompatibility stresses are not taken into account in standard $\sin ^{2} \psi$ method (compare dotted line drawn in Fig. 8b).

The above results agree with our previous conclusions concerning the modelling of cold rolling textures [40,41]. It was found that experimental texture of b.c.c. polycrystals (ferrite) can be predicted by LW model with relatively high $\alpha$, however in the case of f.c.c. structure two characteristic textures exist. So called "copper type texture", characteristic for pure f.c.c. polycrystalline metals with high stacking fault energy (SFE) can be calculated by Taylor type models (or LW model with high value of $\alpha$ ). On the contrary, the "brass type texture" occurring in metal alloys (brass or austenite) with low SFE, is obtained from Sachs type models (or LW model with low values of $\alpha$ ). It can be concluded that crystallographic texture and plastic incompatibility stresses are correctly predicted for cold rolled austenite if a low value of $\alpha$ is assumed in LW model, while a high value of $\alpha$ is required in the case of cold rolled ferritic steel. 
In the further analysis of the experimental data, only the results obtained for the best fit of theoretical data to the measured values were considered (i.e. results of the selfconsistent model were used for analysis in the case of ferritic sample, while LW model with $\alpha=10^{-3}$ was applied for austenite). Comparing plots presented in Figs. 5 and 6, we can notice that the agreement of measured $\langle a(\phi, \psi)\rangle_{\{h k l\}}$ lattice parameter with theoretical results is excellent for cold rolled ferritic steel and a little worse for cold rolled austenite. This is mainly due to difficulty in proper prediction of plastic accommodation, which is more important in austenitic steel than in ferrite. However, for both cold rolled steels the quality of fitting is good enough to find the first order stresses ( $\sigma_{i j}^{I}$ presented in Table 2) and approximate value of $q$ factor which is used to rescale the model stresses (Eq. 19) and to estimate the values of real plastic incompatibility stresses. The second order plastic incompatibility stresses (von Mises values) determined for each grain orientation $\boldsymbol{g}$ are presented in Euler space in Fig. 9. So obtained maps of SODF are compared with experimental ODFs shown by contour lines. We can see that for both studied steels the maxima of ODF correspond to the lowest or medium values of incompatibility stresses, while the highest second order stresses are found for some orientations related to low number of grains (low values of ODF). This can be explained due to small incompatibilities occurring for grains having preferred orientations and deformed similarly like the whole sample (surrounding matrix). In contrary, the grains having orientations far from ODF maxima can accumulate large stresses if their plastic strains are significantly different from the average strain characterizing sample behaviour (however, these strains contribute to the average with low weights).

\subsection{Remarks concerning unique solution for residual stresses}

It should be stated that the measured lattice strains (or $\langle a(\phi, \psi)\rangle_{\{h k l\}}$ vs. $\sin ^{2} \psi$ curves) can correspond to different combination of the first and second order stresses (or even different components of those stresses), i.e. in general case it is not possible to find out a unique stress field from diffraction data. The problem of non unique solution is well known in another examples of interpretation of diffraction results like the structure refinement from measured diffractogram or ODF determination from measured pole figures. In such cases additional constrains should be introduced to reduce the number of possible solution and to find out the real physical one. In the present methodology of stress analysis the constraints are introduced for orientation distribution of the second order stresses, which is in fact determined by theoretical models and scaled by only one parameter adjusting the magnitude of these stresses. Then the model data are strictly verified by fitting procedure, i.e. the shapes of measured nonlinearities on $\langle a(\phi, \psi)\rangle_{\{h k l\}}$ vs. $\sin ^{2} \psi$ curves are reproduced only if the distribution of second order stresses is correctly predicted by the model. In Fig. 10 the results of standard stress analysis, i.e. assuming zero values of second order plastic incompatibility stresses (see Eq. 18) is shown. In such the case a large misfit between experimental and calculated data occurs (small nonlinearities of the $\langle a(\phi, \psi)\rangle_{\{h k l\rangle}$ vs. $\sin ^{2} \psi$ curves are caused by texture influence on DECs). As shown in Figs. 5 and 6, a significant improvement of fitting quality (characterized also by $\chi^{2}$, compare Fig. 8) is obtained using the additional term with correctly predicted the second order stresses scaled by $q$ parameter (Eq. 20). However, if the theoretical data do not correspond to experimental ones, the fitting fails and $\chi^{2}$ parameter significantly increases as shown in Fig. 8. It should be underlined that considerable improvement of fitting results occurs if only one fitting parameter $(q)$ is added to those which are usually adjusted in the standard stress analysis (i.e., the $\sigma_{i j}^{I}$ and $a^{o}$ values). 
In this work the theoretical prediction of the second order stresses is verified by fitting lattice strains for only two reflections for each sample. However, our methodology was already successfully tested using three or even four reflections simultaneously for the interpretation of the TOF diffraction measurements [19]. We can conclude that the theoretical data obtained by the model represent the unique physical solution for the second order stresses (scaled by $q$ factor), which is strictly verified by experimental results.

\subsection{Stress evolution during recovery process}

The recovery process in cold rolled ferritic and austenitic steels causes a gradual reduction of dislocations density correlated with a decrease of diffraction peak width, as shown in Fig. 7. On the other hand, insignificant changes of crystallographic textures up to $600{ }^{\circ} \mathrm{C}$ for ferrite and up to $650^{\circ} \mathrm{C}$ for austenite (Figs. 3 and 4), indicate the ranges of annealing temperature for which the recrystallization process still does not occur. In this section the relaxation of the first and the second order stresses during recovery is discussed and compared with the evolution of the integral widths of diffraction peaks.

Changes of slope and effects of nonlinearity in the $\langle a(\phi, \psi)\rangle_{\{h k l\}}$ vs. $\sin ^{2} \psi$ curves, shown in Figs. 5 and 6 for different temperatures, reflect modifications of the first order residual stress (macrostress) and of the second order incompatibility stress values, respectively. An excellent agreement between measured values and fitted theoretical curves confirms that only the magnitude of incompatibility stresses changes during annealing and our procedure of stress analysis works correctly for all temperatures and for both studied materials (see Figs. 5 and 6). The observed nonlinearities of $\langle a(\phi, \psi)\rangle_{\{h k l\}}$ vs. $\sin ^{2} \psi$ curves are caused by a strong anisotropy (i.e., dependence on crystal orientation) of the second order plastic incompatibility stresses in both cold rolled steels. Their anisotropy is also well visible on SODF shown in Fig. 9.

Evolution of the macrostresses ( $\sigma_{11}^{I}$ in RD and $\sigma_{22}^{I}$ in TD) and of the second order plastic incompatibility stress (mean von Mises value) vs. annealing temperature is shown in Fig. $11\left(\overline{\sigma_{\text {Mises }}^{I I(p i)}}=\frac{1}{N_{g}} \sum_{\mathrm{g}=1}^{\mathrm{N}_{\mathrm{g}}} \sigma_{\text {Mises }}^{I I g(p i)}(\boldsymbol{g})\right.$ where $N_{g}$ is the number of grains). Both kinds of stress were estimated using the fitting procedure based on Eq. 20. In the ferritic steel the relaxation of macrostress $\left(\sigma_{11}^{I}\right.$ and $\sigma_{22}^{I}$ ) started in relatively low temperature (quite below $200{ }^{0} \mathrm{C}$ ), while plastic incompatibility stresses $\left(\overline{\sigma_{\text {Mises }}^{I I(p i)}}\right)$ started to relax at temperatures above $200{ }^{0} \mathrm{C}$. It can be noticed that the residual stresses relaxed completely due to the start of recrystalization over $600{ }^{0} \mathrm{C}$ (confirmed by beginning of texture transformation in Fig. 3), which is also visible as the stabilization of integral peak width between $600{ }^{\circ} \mathrm{C}$ and $800{ }^{\circ} \mathrm{C}$ (Fig. 7). On the contrary, in austenitic steel both kinds of stress relaxed very little till $400{ }^{\circ} \mathrm{C}$, but this process strongly accelerated above $400{ }^{0} \mathrm{C}$. Finally, the first order stresses $\left(\sigma_{11}^{I}\right.$ and $\sigma_{22}^{I}$ ) in austenite relax faster with temperature and they disappear completely at $650^{\circ} \mathrm{C}$ (however, no significant texture change is observed - Fig. 4), while incompatibility stresses are still present at this temperature (Figs. 11).

The above observations agree very well with the results presented in the paper of Wang et al. [14], where the relaxation of the first and the second order stresses after annealing of austeno-ferritic steel at $500^{\circ} \mathrm{C}$ was studied (other temperatures were not considered). At this temperature, the second order incompatibility stresses completely relaxed in ferritc phase but only decreased in austenite. 
Evolution of specific stored elastic energy (SSEE) $\overline{W^{\text {tot }}}$ versus annealing temperature is presented in Fig. 12. SSEE was calculated as:

$$
\overline{W^{t o t}}=\frac{1}{N_{g}} \sum_{g=1}^{N_{g}} W^{g(t o t)}(\boldsymbol{g})
$$

where: $W^{g(t o t)}(\boldsymbol{g})=\frac{1}{2} \sigma_{i j}^{g}(\boldsymbol{g}) s_{i j k l}^{\mathrm{g}}(\boldsymbol{g}) \sigma_{k l}^{g}(\boldsymbol{g})$ and $\sigma_{i j}^{g}(\boldsymbol{g})$ is a total grain stress calculated as a superposition of $\sigma_{i j}^{I l(p i)}(\boldsymbol{g})$ and a stress induced by $\sigma_{i j}^{I}$ in the considered grain.

The observed rapid decrease of SSEE confirms that residual stress relaxation is thermally activated and it occurs after some temperature threshold, which is lower than $200^{\circ} \mathrm{C}$ for ferrite and equal approximately to $400^{\circ} \mathrm{C}$ for austenite. Also faster relaxation of the first order stresses in comparison with plastic incompatibility stresses is confirmed by the behaviour of SSEE components, calculated separately for macrostresses $\left(\sigma_{11}^{I}\right.$ and $\left.\sigma_{22}^{I}\right)$ and plastic incompatibility stresses $\left(\sigma_{i j}^{I g(p i)}(\boldsymbol{g})\right)$. These mean values are denoted by $\overline{W^{I I(p i)}}$ and $\overline{W^{I}}$, respectively, and their evolution vs. annealing temperature is shown in Fig. 12.

Different rates of relaxation process in austenitic and ferritic steels can be explained considering two kinds of dislocation movements: conservative (slip/twinning) and nonconservative (climb) ones. A higher number of available slip planes in ferrite than in austenite (i.e., $\{110\},\{112\}$ in comparison to $\{111\}$ ) can be responsible for easier cross slip of dislocations, which facilitates their annihilation. Moreover, the cross slip easiness is proportional to SFE. Higher SFE makes difficult dissociation of dislocations and consequently increases the rate of dislocation cross slip and climb. In metals of low SFE such as austenitic stainless steel, cross slip and climb are much more difficult. In consequence, only a small recovery can be observed in austenite just before recrystallization, so directly before this process the energy stored in dislocation stress fields is relatively high. Moreover, the plastic incompatibility stresses still remain in the sample, even for temperature of $650^{\circ} \mathrm{C}$. The stored elastic energy supports thermal activation and accelerates the recrystallization processes. On the contrary, in metals of high SFE such as ferritic steel, climb and cross-slip are frequent, and recovery is well separated from recrystallization process, because it occurs in much lower temperature [53]. The lower energy accumulated in the microstructure directly before recrystallization is responsible for lower rate of recrystallization in ferrite.

We can also conclude that the stress relaxation during recovery can be explained in different ways for the first and the second order stresses. The macrostresses $\left(\sigma_{i j}^{I}\right)$ caused by interaction of large sample volumes introduce grain stresses which can be relaxed at lower temperatures or faster, e.g., by polygonisation process. During this process the thermally activated movement of dislocations leads to creation of low angle boundaries dividing polycrystalline grains into smaller parts. Annihilation of dislocations during this process causes some decrease of dislocation density, observed as a reduction of integral width of diffraction peak (Fig. 7), while texture does not change significantly (Figs. 3 and 4). In the case of ferritic sample significant relaxation of the first order stresses starts below $200^{\circ} \mathrm{C}$, while the incompatibility stresses do not change at this temperature (Figs. 11 and 12). For austenite both types of stresses start to relax at approximately the same temperature, however faster relaxation occurs for the first order stresses. Poligonisation mechanism, is probably not sufficient to relax strongly anisotropic plastic incompatibility stresses $\left(\sigma_{i j}^{\operatorname{Ig}(p i)}\right)$ created 
by misfits occurring between grains with different crystal orientations and, consequently, separated by high angle boundaries. To relax these stresses higher temperatures, causing more significant rearrangement of dislocations structure (including their annihilation), are required. This is clearly seen in both materials: in ferritic steel the plastic incompatibility stresses start to relax above $200{ }^{\circ} \mathrm{C}$ and in austenitic steel - above $400{ }^{\circ} \mathrm{C}$. Moreover, the relaxation of incompatibility stresses in austenite is slower than the first order stress. The decrease of peak width confirms that the relaxation processes are connected with continuous reduction of dislocation density (Fig. 7).

\section{General conclusions}

The macrostreses and the second order incompatibility stresses were determined in cold rolled and annealed austenitic and ferritic steels using diffraction measurements and models of elastoplastic deformation. The following conclusions can be formulated:

(1) Analysis of incompatibility residual stresses from nonlinearities of $\langle a(\phi, \psi)\rangle_{\{h k l\}}$ vs. $\sin ^{2} \psi$ plots shows a type of interaction occurring between grains during elastoplastic deformation. It was found that the self-consistent model correctly predicts plastic incompatibility stresses in ferritic steel. However, this type of stress in austenite can be modelled only using LW model with low plastic accommodation parameter $\alpha<$ $10^{-3}$ (close to Sachs model). This difference between materials was confirmed by other authors studying evolution of crystallographic texture.

(2) Orientation distribution of incompatibility stresses (visualized by SODF) created during elastoplastic deformation can be determined from $\langle a(\phi, \psi)\rangle_{\{h k l\}}$ vs. $\sin ^{2} \psi$ plots. It was shown that the highest residual stresses are accumulated in the grains having orientations far from the main ODF maxima. Low incompatibility stresses are generated in grains with preferred crystal orientations.

(3) The relaxation of the residual stresses occurs during recovery process. This process is thermally activated and begins at lower temperature for ferritic steel in comparison with austenite. These differences can be explained by the facility of dislocation cross slip and climb, which depends on crystal structure and on SFE.

(4) Relaxation of the first order stresses occurs at lower temperatures than relaxation of plastic incompatibility stresses. Correlation of stress evolution with the variation of integral width of diffraction peak shows that small rearrangement of dislocations leads to macrostresses relaxation, while significant decrease of dislocation is necessary to relax plastic incompatibility stresses.

As a general conclusion it can be stated that the first and the second order residual stresses can be determined quantitatively if diffraction measurements are combined with deformation model predictions. Theresidual stresses and orientation distribution of the elastic energy contain important information for understanding the deformation and recrystallization mechanisms as well as damage initialization. It was found that two kinds of residual stresses (the first and the second order) relax differently during annealing and this thermally activated relaxation depends on the stacking fault energy of the studied material.

Acknowledgements: This work was supported by the Polish Ministry of Science and Higher Education (MNiSW), by Polonium Project (7827/R09/R10) and by the Grant Nr: 712/N-POLONIUM/2010/0. 


\section{References}

[1] G. Maeder, J.L. Lebrun and J.M. Sprauel, Non Dest. Testing Int. 10 (1981) p.235.

[2] V. Hauk, Structural and residual stress analysis by nondestructive methods, Elsevier, Amsterdam, 1997.

[3] I.C. Noyan and J.B. Cohen, Residual Stress: Measurement by Diffraction and Interpretation, New York: Springer, Verlag, 1987.

[4] U. Welzel, J. Ligot, P. Lamparter, A.C. Vermeulen and E.J. Mittemeijer, J. Appl. Cryst. 38 (2005) p.1.

[5] J.G.M. Berkum, A.C. van Vermeulen, R. Delhez, Th.H. Keijser and E.J. Mittemeijer,

J. Appl. Cryst. 27 (1994) p.345.

[6] B. Clausen, T. Lorentzen, M.A.M. Bourke and M.R. Daymond, Mater. Sci. Eng. A 259 (1999) p.17.

[7] D. Dye, H.J. Stone and R.C. Reed, Acta Mater. 49 (2001) p.1271.

[8] S. Cai, M.R. Daymond and R. A. Holt, Acta Mater. 57 (2009) p.407.

[9] V. Hauk, W.K. Krug, W.M. Oudelhoven and L. Pintschovius, Z. Metallkde. 79 (1988) p.159.

[10] R. Dakhlaoui, V. Klosek, M.-H. Mathon and B. Marini, Acta Mater. 58 (2010) p.499.

[11] H.J. Bunge, Texture Analysis in Material Science: Mathematical Methods, London: Butterworths, 1982.

[12] H. Behnken, Phys. Stat. Sol. A, 177 (2000) p.401.

[13] H. Behnken, Mater. Sci. Forum 404-407 (2002) p.275.

[14] Y.D. Wang, R. Lin Peng, X.-L. Wang and R.L. McGreevy, Acta Mater. 50 (2002) p.1717.

[15] Y.D. Wang, X.-L. Wang, A.D. Stoica, J.W. Richardson and R. Lin Peng, J. Appl. Cryst. 36 (2003) p.14.

[16] X.-L. Wang, Y.D. Wang, A.D. Stoica, D.J. Horton, H. Tian, P.K. Liaw, H. Choo, J.W. Richardson, E. Maxey, Mater. Sci. Eng. A 399 (2005) p.114.

[17] A. Baczmański, K. Wierzbanowski, P. Lipiński, R.D. Helmholdt, G. Ekambaranathan, and B. Pathiraj, Phil. Mag. A, 69 (1994) p.437.

[18] A. Baczmański, C. Braham and W. Seiler, Phil. Mag. 83 (2003) p.3225.

[19] S. Wroński, A. Baczmański, R. Dakhlaoui, C. Braham, K. Wierzbanowski, E.C. Oliver, Acta Mater. 55 (2007) p.6219.

[20] K. Inal, P. Gergaud, M. François, J.-L. Lebrun, Scand. J. Metall. 28 (1999) p.139.

[21] D. Gloaguen, M. François and R. Guillen, J. Appl. Cryst. 37 (2004) p.934.

[22] D. Gloaguen, T. Berchi, E. Girard and R. Guillen, Acta Mater. 55 (2007) p.4369.

[23] A. Baczmański, P. Lipinski, A. Tidu, K. Wierzbanowski and B. Pathiraj, J. Appl. Cryst. 41 (2008) p.854. 
[24] A. Baczmański, N. Hfaiedh, M. François and Wierzbanowski, Mater. Sci. and Eng. A 501 (2009) p.153.

[25] A. Baczmański, K. Wawszczak, W. Seiler, C. Braham, S. Wroński, M. Wróbel and K. Wierzbanowski, Mater. Sci. Forum 638-642 (2010) p.3827.

[26] K. Piękoś, J. Tarasiuk, K. Wierzbanowski and B. Bacroix, Comp. Mat. Sci. 42 (2008) p. 584.

[27] K. Piękoś, J. Tarasiuk, K. Wierzbanowski and B. Bacroix, Comp. Mat. Sci. 42 (2008) p. 36.

[28] R. Dakhlaoui, A. Baczmanski, C. Braham, S. Wronski, K. Wierzbanowski and E.C. Oliver, Acta Mater., 54 (2006) p. 5027.

[29] P. J. Withers, Rep. Prog. Phys., 70 (2007) p. 2211.

[30] C.D.M. Liljedahl, J. Brouard, O. Zanellato, J. Lin, M.L. Tan, S. Ganguly, P.E. Irving, M.E. Fitzpatrick, X. Zhang and L. Edwards, Int. J. Fatigue, 31 (2009) p. 1081.

[31] L. Le Joncour, B. Panicaud, A. Baczmański, M. Francois, C. Braham, A. Paradowska, S. Wroński and R. Chirone, Mech. Mater., 42 (2010) p. 1048.

[32] K. Wierzbanowski, A. Baczmański, R. Wawszczak, J. Tarasiuk, Ph. Gerber, B. Bacroix and A. Lodini, Mat. Scie. Tech. 21 (2005) p.46.

[33] N. Zotov, J. Feydt and A. Ludwig, Thin Solid Films, 517 (2008) p. 531.

[34] B.X. Feng, X.N. Mao, G.J. Yang, L.L. Yu and X.D. Wu, Mater. Scie. Eng. A, 512 (2009) p. 105.

[35] J. Epp, H. Surm, T. Hirsch, F. Hoffmann, J. Mater. Process. Techn., (2010), in press doi:10.1016/j.jmatprotec.2010.11.022

[36] P. Lipinski and M. Berveiller, Int. J. of Plasticity 5 (1989) p.149.

[37] P. Lipinski, M. Berveiller, E. Reubrez and J. Morreale, Arch. Appl. Mech. 65 (1995) p.291.

[38] P. Zattarin, A. Baczmański, P. Lipiński and K. Wierzbanowski, Arch. Metall. 45 (2000) p.163.

[39] T. Leffers, Phys. Stat. Sol. 25 (1968) p.337.

[40] K. Wierzbanowski, A. Baczmański, P. Lipinski and A. Lodini, Arch. Metall. Mater. 52 (2007) p.77.

[41] K. Wierzbanowski, J. Jura, W.G. Haije, R.B. Helmholdt, Cryst. Res. Tech. 27 (1992) p.513.

[42] R. Hill, J. Mech. Phys. Solids, 13 (1965) p.89.

[43] M. Berveiller, A. Zaoui, Méthodes self consistantes en mécanique des solides

hétérogénés, dans: Comportements rhéologiques et structure des matériaux (Editeurs: C.

Huet, A. Zaoui), pp. 175-200, Paris, Editions de ENPC (1981)

[44] G. Sachs, Zeit. Der V.D.I., 72 (1928) 7 p.39.

[45] G.I. Taylor, J. Inst. Metals, 62 (1938) p.307. 
[46] S.J. Skrzypek, A. Baczmański, W. Ratuszek and E. Kusior, J. Appl. Cryst. 34 (2001) p.427.

[47] C. Tome, G.R. Canova, U.F. Kocks, N. Christodoulou, J.J. Jonas, Acta Metall. 32 (1984) 1637.

[48] P. Franciosi, M. Berveiller, A. and Zaoui, Acta Met. 28 (1980) 273.

[49] J.D. Eshelby, Proc. R. Soc. Lond. A 241 (1957) 398.

[50] J.S. Kallend, U.F. Kocks, A.D. Rollet and H.R. Wenk, Operational Texture Analysis, Raport LA-UR-90-2852, Center for Material Sciences, Los Alamos National Laboratory, USA, 1990.

[51] G. Simmons and H. Wang, Crystal Elastic Constants and Calculated Aggregate Properties: A Handbook. Cambridge, MA/London: The MIT Press, 1971.

[52] C.N. Reid, Deformation Geometry for Material Scientists, Pergamon Press, Oxford, 1973.

[53] F.J. Humphreys and M. Hatherly, Recrystallization and Related Annealing Phenomena, Elsevier Science Ltd., 2004. 
Table 1. Parameters used in the deformation models.

\begin{tabular}{|c|c|c|c|c|c|c|c|}
\hline \multirow[t]{3}{*}{ Sample } & \multirow{3}{*}{$\begin{array}{c}\text { Initial critical } \\
\text { resolved shear } \\
\text { stress } \\
\tau_{0}(\mathrm{MPa})\end{array}$} & \multirow{3}{*}{$\begin{array}{c}\text { Hardening } \\
\text { parameter } \\
H(\mathrm{MPa})\end{array}$} & \multirow{2}{*}{\multicolumn{3}{|c|}{$\begin{array}{c}\text { Self-consistent model } \\
\text { Single crystal elastic } \\
\text { constants (GPa) }\end{array}$}} & \multicolumn{2}{|c|}{ LW model } \\
\hline & & & & & & \multirow{2}{*}{$\begin{array}{c}\text { elastic shear } \\
\text { modulus } \\
\mu_{e}(\mathrm{GPa})\end{array}$} & \multirow{2}{*}{$\begin{array}{l}\text { Elastoplastic } \\
\text { accommodation } \\
\text { matrix } u_{i j}\end{array}$} \\
\hline & & & $\mathrm{C}_{11}$ & $\mathrm{C}_{12}$ & $\mathrm{C}_{44}$ & & \\
\hline Austenitic steel & 200 & 80 & 197.5 & 124.5 & 122 & 80 & $\begin{array}{l}u_{13}=u_{13}=0 \\
u_{i j}=1 \text { for other } i j\end{array}$ \\
\hline Ferritic steel & 200 & 80 & 231 & 134.4 & 116.4 & 80 & $u_{i j}=1$ for all $i j$ \\
\hline
\end{tabular}

Table 2. Values of the first order stresses determined for cold rolled samples $\left(\sigma_{33}^{I}=0\right)$.

\begin{tabular}{|c|c|c|c|c|c|c|c|}
\hline \multirow{2}{*}{ Sample } & $\begin{array}{c}\text { Model used in } \\
\text { analysis of } \\
\text { experimental data }\end{array}$ & \multicolumn{5}{|c|}{ Macrostresses (first order streses) } & \multirow{2}{*}{$\chi^{2}$} \\
\cline { 2 - 7 } & & $\sigma_{11}^{I}$ & $\sigma_{22}^{I}$ & $\sigma_{12}^{I}$ & $\sigma_{13}^{I}$ & $\sigma_{23}^{I}$ & \\
\hline $\begin{array}{c}\text { cold rolled } \\
\text { ferrite }\end{array}$ & self-consistent & -124.0 & -30.2 & 8.9 & -4.2 & -0.8 & 2.2 \\
\hline cold rolled & $\mathrm{LW}\left(\alpha=10^{-3}\right)$ & -38.7 & -70.0 & -19.0 & -4.1 & -0.7 & 9.7 \\
austenite & & \pm 6.2 & \pm 7.8 & \pm 6.0 & \pm 4.0 & \pm 4.0 & \\
\hline
\end{tabular}




\section{FIGURES CAPTIONS}

Figure 1. Scheme of plastic behaviour of two exemplary grains having various orientations of slip systems with respect to the local stress $\sigma$. After plastic deformation and unloading of the applied stresses $(\Sigma \rightarrow 0)$ the grains do not fit to the surrounding matrix and the plastic incompatibility stresses $\sigma_{i j}^{I I g}$ are generated.

Figure. 2. Orientation of the scattering vector in relation to the directions of rolling defined by $\psi$ and $\phi$ angles (RD: rolling directions; TD: transverse directions; ND: normal directions).

Figure 3. Orientation distribution functions for cold rolled ferritic steel annealed at different temperatures. Sections through Euler space at intervals $5^{\circ}$ along the $\varphi_{2}$ axis are presented.

Figure 4. Orientation distribution functions for cold rolled austenitic steel annealed at different temperatures. Sections through Euler space at intervals $5^{\circ}$ along the $\varphi_{2}$ axis are presented.

Figure 5. Measured lattice parameters (points) and theoretical predictions of self-consistent model (lines) fitted using modified $\sin ^{2} \psi$ method. Results for cold rolled and annealed ferritic steel obtained with 211 and 200 reflections are shown vs. $\sin ^{2} \psi$ for different values of $\phi$ angle.

Figure 6. Measured lattice parameters (points) and theoretical predictions of LW model ( $\alpha=10^{-3}$; lines) fitted using modified $\sin ^{2} \psi$ method. Results for cold rolled and annealed austenitic steel obtained with 311 and 220 reflections are shown vs. $\sin ^{2} \psi$ for different values of $\phi$ angle.

Figure 7. Integral width of diffraction peaks for different temperatures of annealing. Results for ferritic steel (211 and 200 reflections) and austenitic steel (200 reflection) are shown.

Figure 8. Quality of fitting (expressed by $\chi^{2}$ ) obtained in modified $\sin ^{2} \psi$ method (Eq. 20) versus elastoplastic accommodation level characterized by $\alpha$ parameter in LW model. The $\chi^{2}$ obtained with self-consistent model (*) and using standard $\sin ^{2} \psi$ method based on Eq. 18 (dotted line) are also shown for comparison.

Figure 9. Maps of plastic incompatibility stresses (von Mises values in MPa) presented in Euler space (SODF) for cold rolled steels. ODF is also shown by contour lines. Sections through Euler space at intervals $5^{\circ}$ along the $\varphi_{2}$ axis are presented.

Figure. 10. Measured lattice parameters (points) and theoretical predictions obtained when the influence of plastic incompatibility stresses was neglected in standard $\sin ^{2} \psi$ method (see Eq. 18). Example results for ferritic and austenitic steels are shown.

Figure 11. Evolution of macrostress $\left(\sigma_{11}^{I}\right.$ and $\sigma_{22}^{I}$ ) and of plastic incompatibility stresses 
(mean von Mises stress $\overline{\sigma_{\text {Mises }}^{I I(p i)}}$ calculated from $\sigma_{i j}^{I I g(p i)}$ ) for different temperatures of annealing. Results obtained for ferritic and austenitic steels are shown.

Figure 12. Evolution of the average stored specific elastic energy for cold rolled and annealed steel samples. The SSEE corresponding to total stresses $\left(\overline{W^{\text {tot }}}\right)$, plastic incompatibility stresses $\left(\overline{W^{I I(p i)}}\right)$ and macrostresses $\left(\overline{W^{I}}\right)$ are presented. 


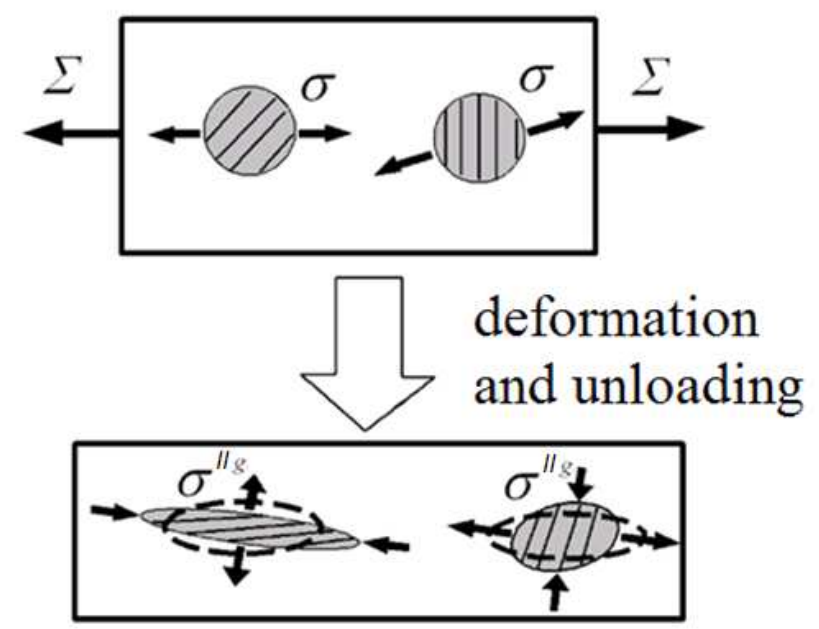

Fig. 1.

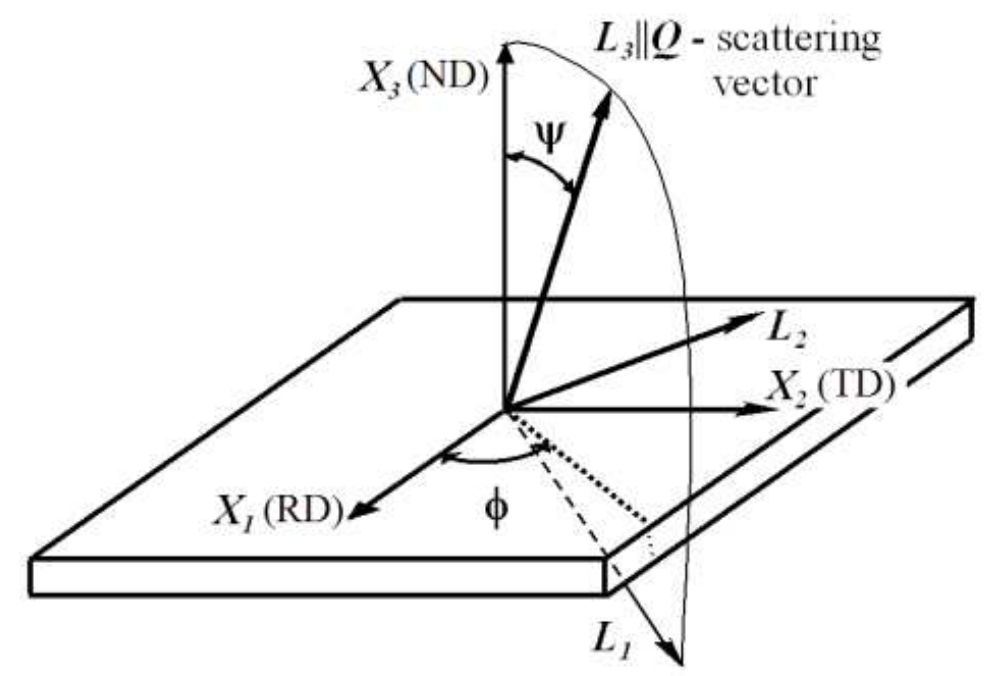

Fig. 2. 


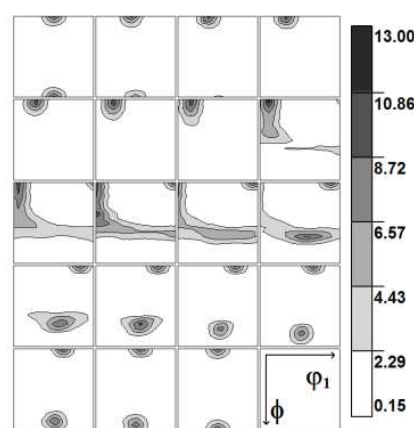

cold rolled

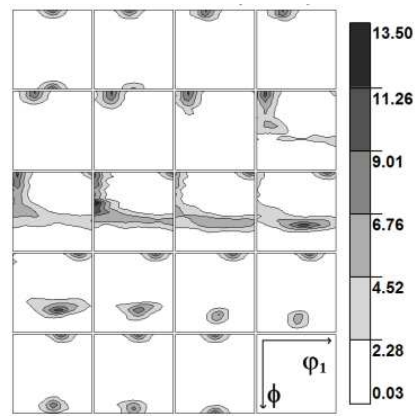

rolled \& annealed $\left(\mathrm{T}=200^{\circ} \mathrm{C}\right)$

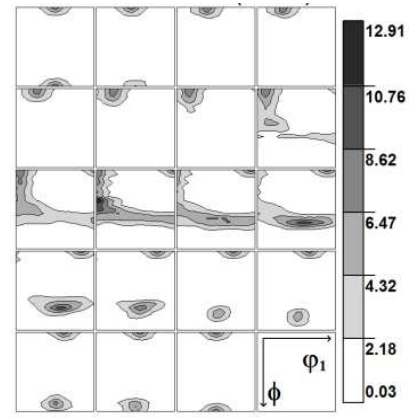

rolled \& annealed $\left(\mathrm{T}=400^{\circ} \mathrm{C}\right)$



Fig. 3.

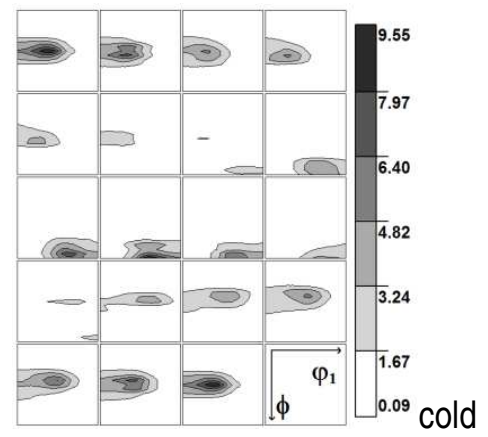

rolled



\& annealed $\left(\mathrm{T}=500^{\circ} \mathrm{C}\right)$

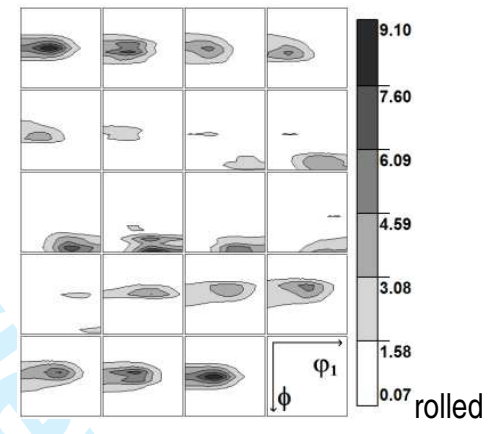

\& annealed $\left(T=600^{\circ} \mathrm{C}\right)$

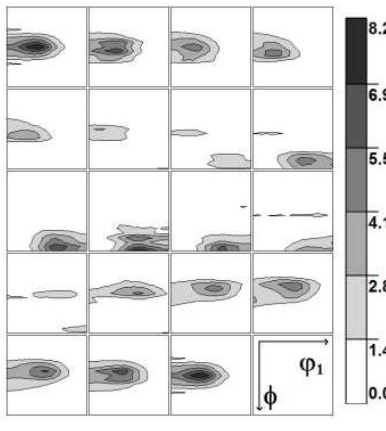

\& annealed $\left(\mathrm{T}=650^{\circ} \mathrm{C}\right)$

Fig. 4. 


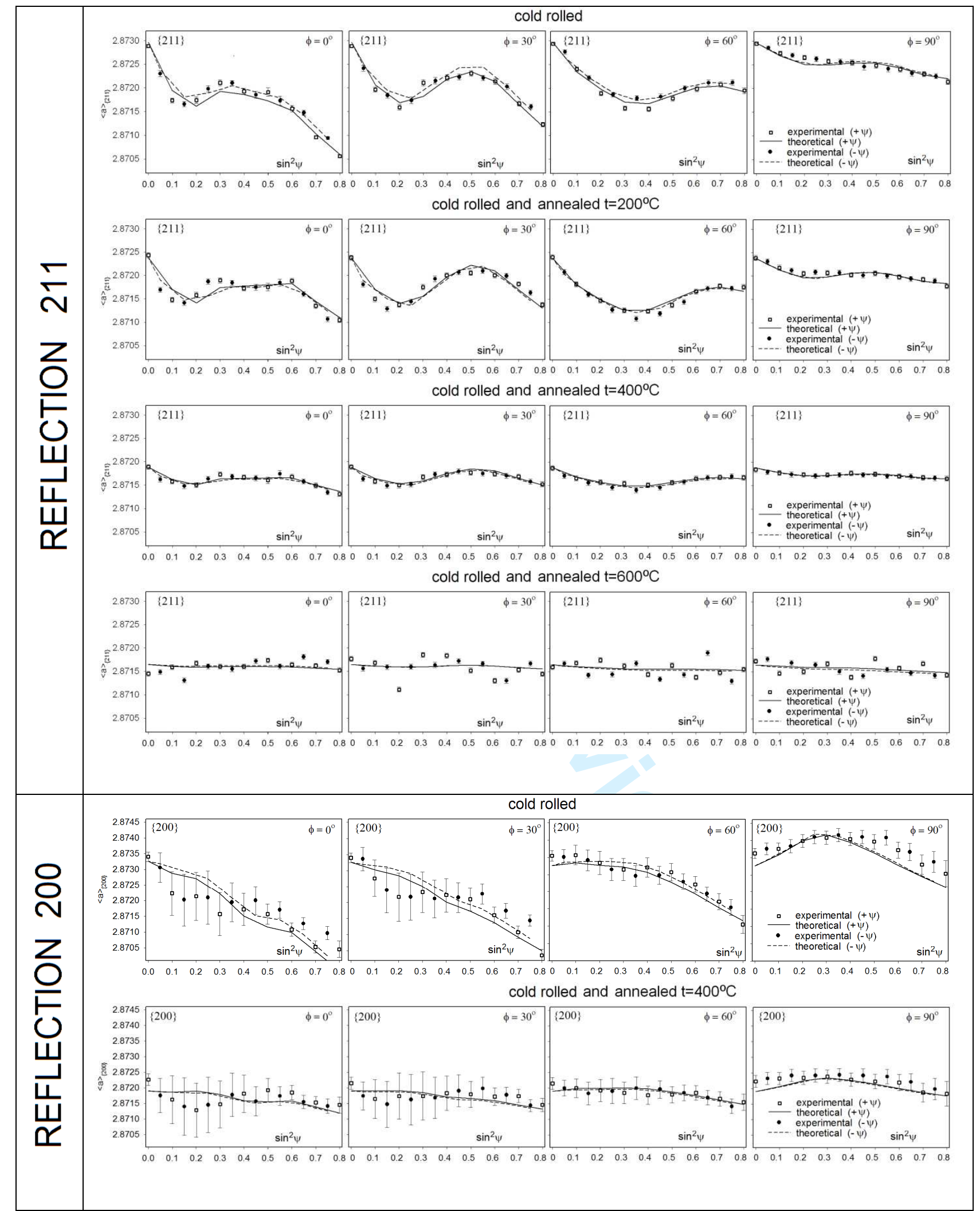

Fig. 5. 


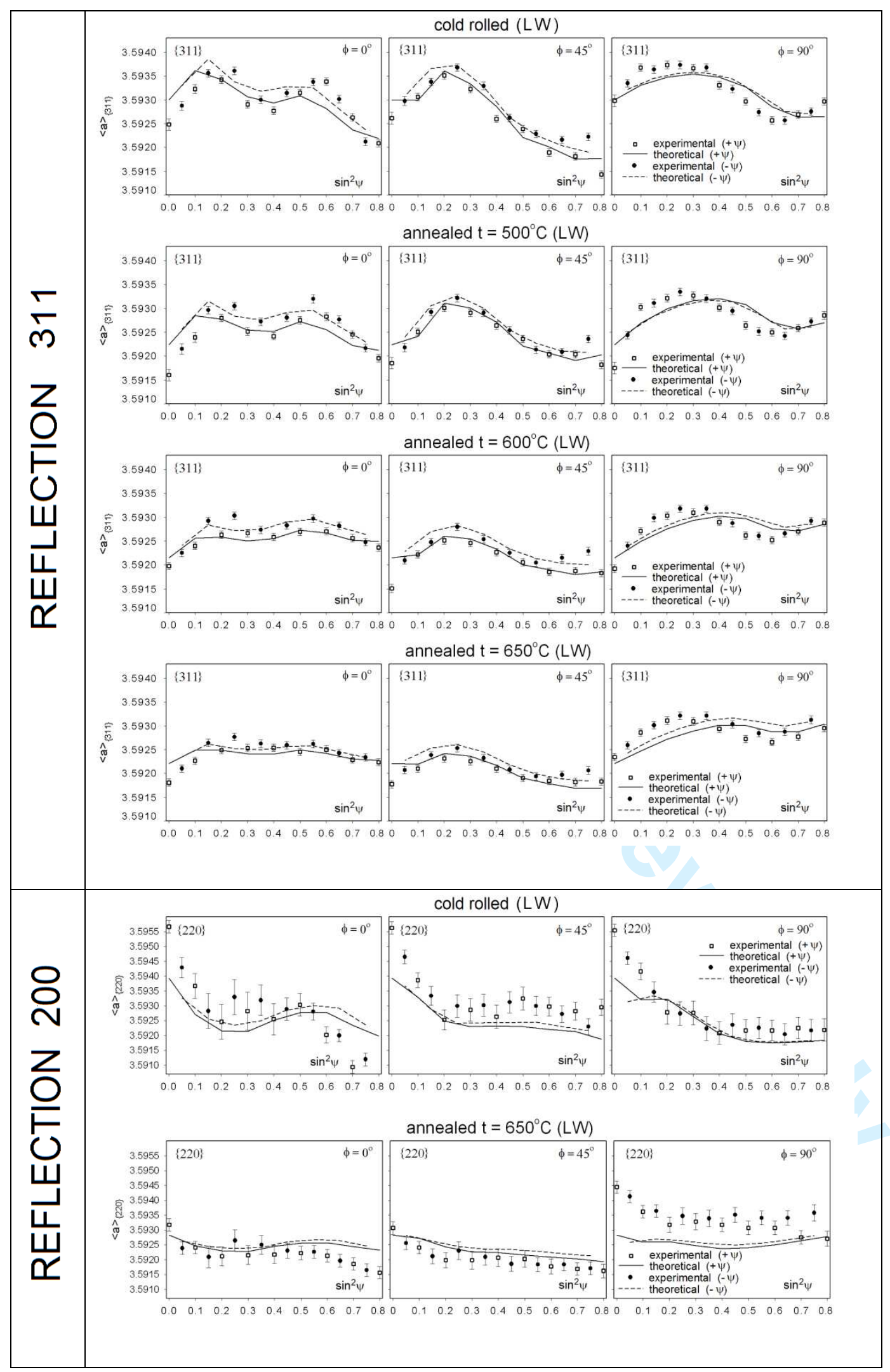

Fig. 6. 


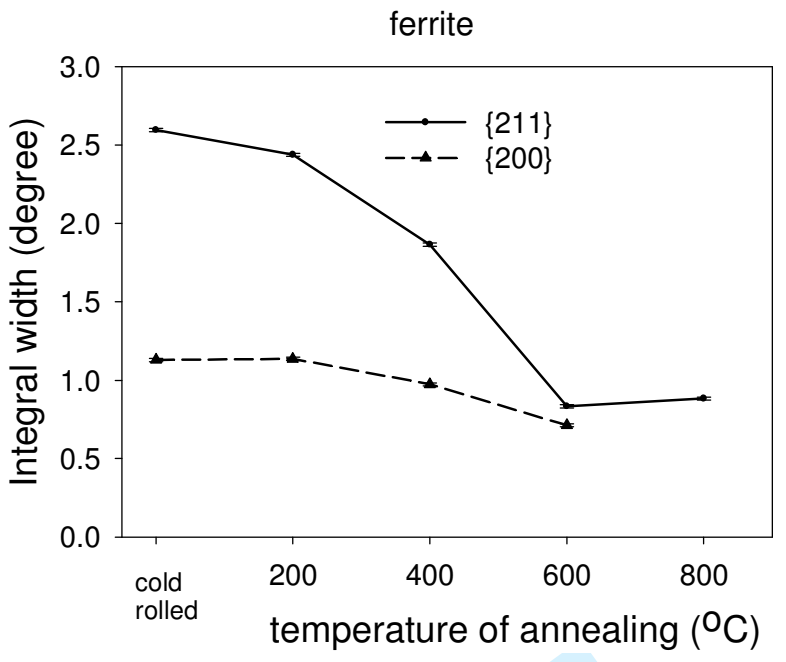

a)

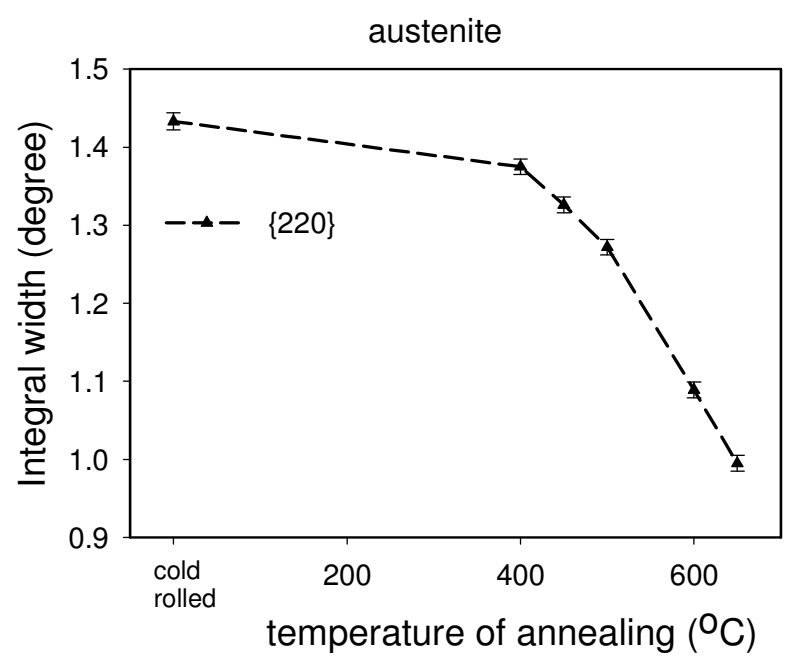

b)

Fig.7.
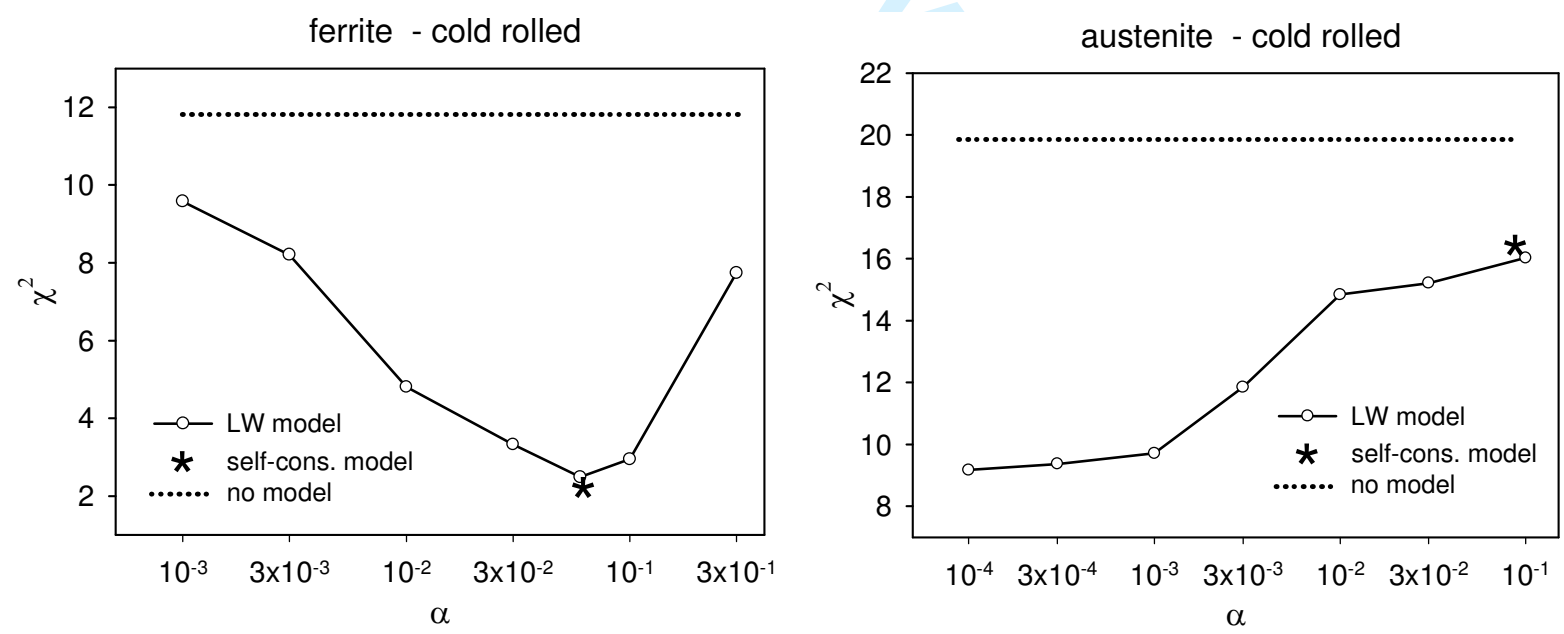

a)

b)

Fig. 8. 


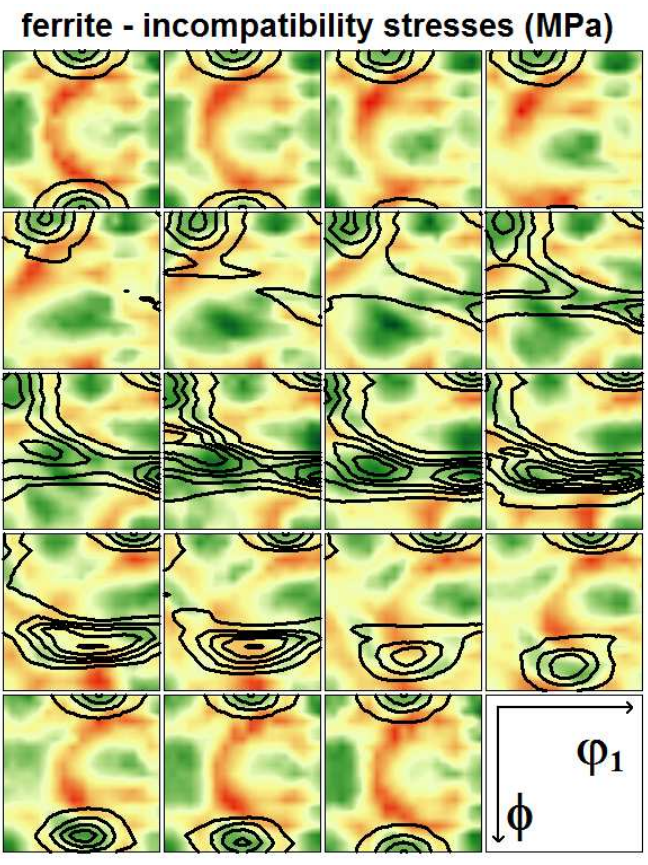

a) austenite - incompatibility stress (MPa)

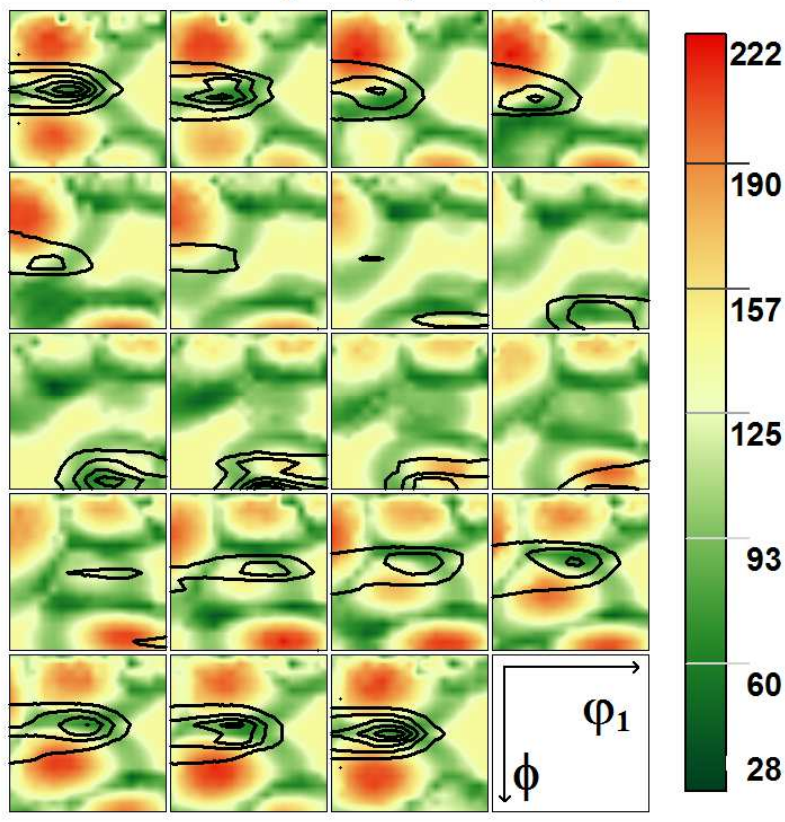

b)

Fig. 9.

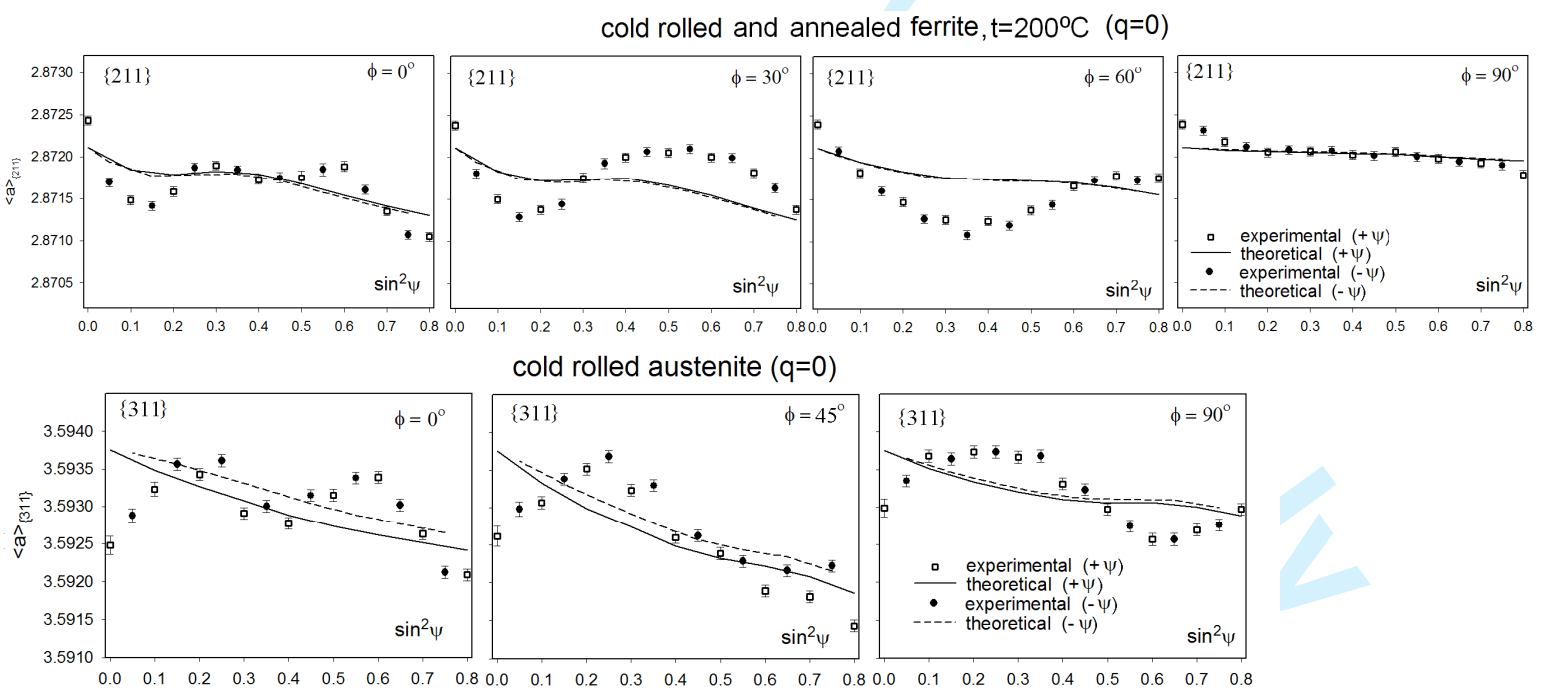

Fig. 10. 


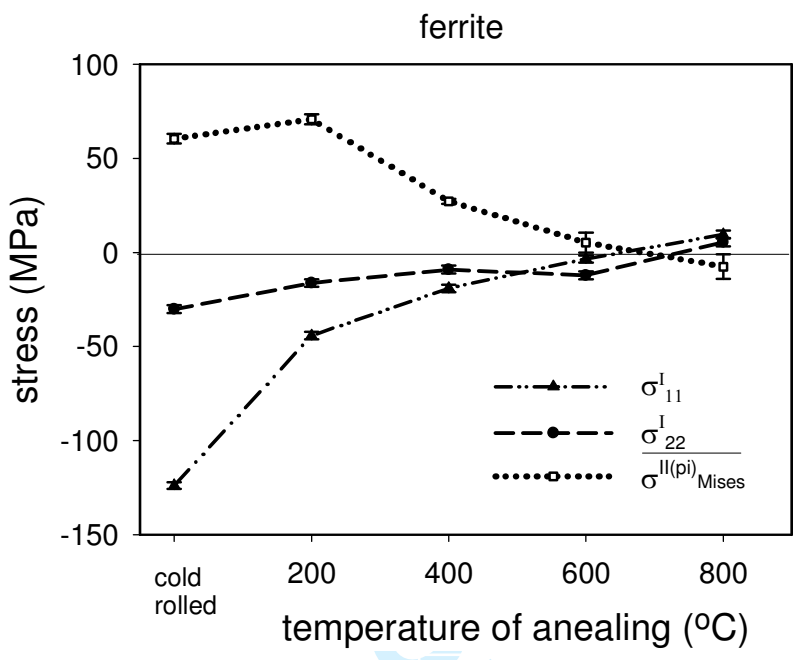

a)

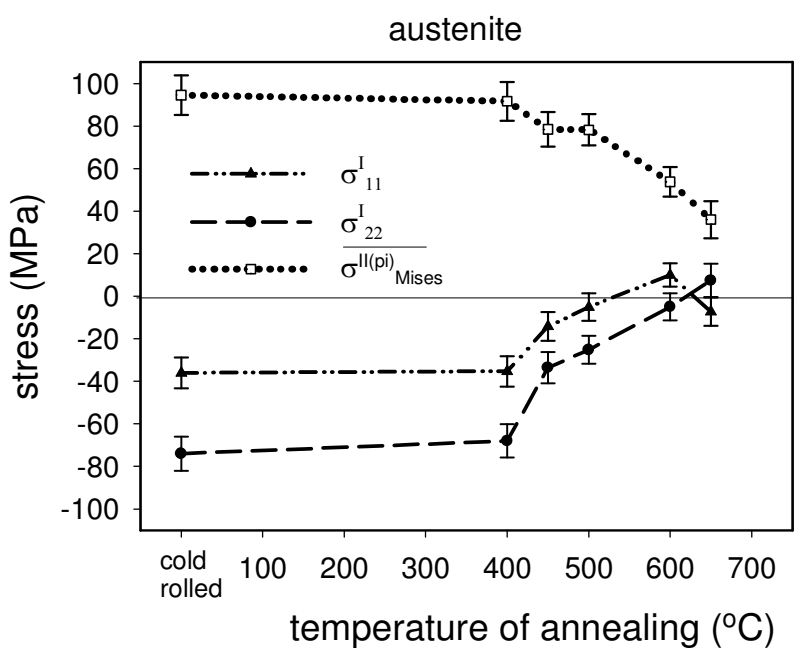

b)

Fig. 11.

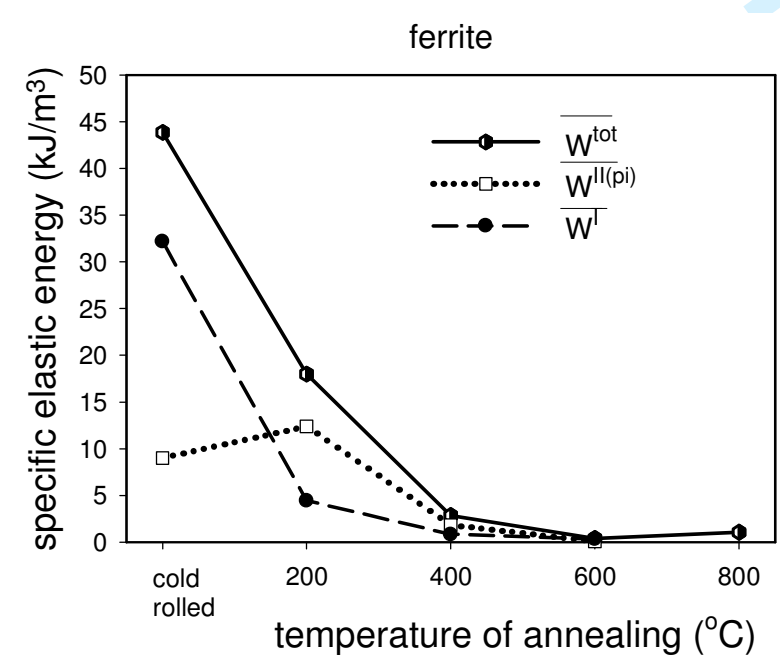

a)

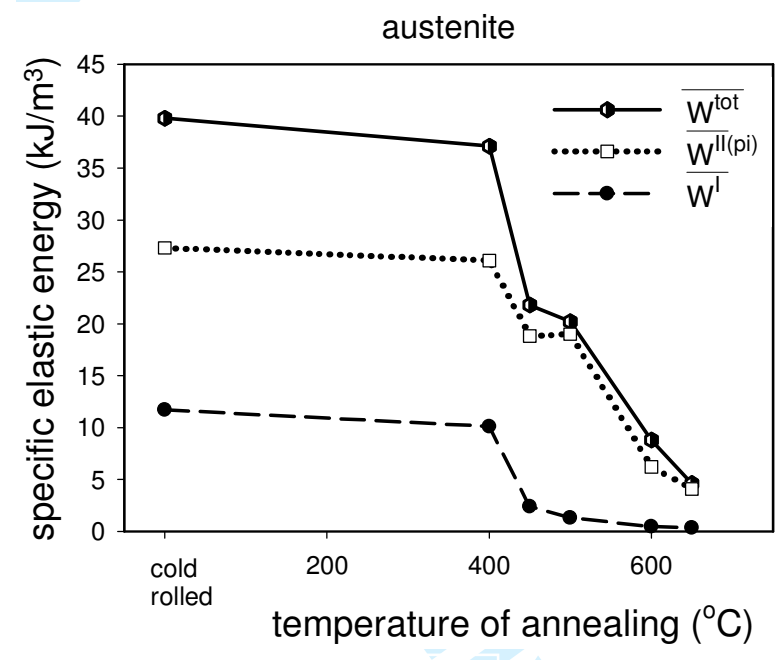

b)

Fig. 12. 